\title{
Obesity Elicits Interleukin 1-Mediated Deficits in Hippocampal Synaptic Plasticity
}

\author{
Joanna R. Erion, ${ }^{1 \star}$ Marlena Wosiski-Kuhn, ${ }^{1 *}$ Aditi Dey, ${ }^{1}$ Shuai Hao, ${ }^{1}$ Catherine L. Davis, ${ }^{1,2}$ Norman K. Pollock, ${ }^{2}$ \\ and Alexis M. Stranahan ${ }^{1}$ \\ ${ }^{1}$ Department of Physiology and ${ }^{2}$ Georgia Prevention Institute, Medical College of Georgia, Georgia Regents University, Augusta, Georgia 30912
}

\begin{abstract}
Adipose tissue is a known source of proinflammatory cytokines in obese humans and animal models, including the $d b / d b$ mouse, in which obesity arises as a result of leptin receptor insensitivity. Inflammatory cytokines induce cognitive deficits across numerous conditions, but no studies have determined whether obesity-induced inflammation mediates synaptic dysfunction. To address this question, we used a treadmill training paradigm in which mice were exposed to daily training sessions or an immobile belt, with motivation achieved by delivery of compressed air on noncompliance. Treadmill training prevented hippocampal microgliosis, abolished expression of microglial activation markers, and also blocked the functional sensitization observed in isolated cells after ex vivo exposure to lipopolysaccharide. Reduced microglial reactivity with exercise was associated with reinstatement of hippocampus-dependent memory, reversal of deficits in long-term potentiation, and normalization of hippocampal dendritic spine density. Because treadmill training evokes broad responses not limited to the immune system, we next assessed whether directly manipulating adiposity through lipectomy and fat transplantation influences inflammation, cognition, and synaptic plasticity. Lipectomy prevents and fat transplantation promotes systemic and central inflammation, with associated alterations in cognitive and synaptic function. Levels of interleukin $1 \beta$ (IL1 $\beta$ ) emerged as a correlate of adiposity and cognitive impairment across both the treadmill and lipectomy studies, so we manipulated hippocampal IL1 signaling using intrahippocampal delivery of IL1 receptor antagonist (IL1ra). Intrahippocampal IL1 ra prevented synaptic dysfunction, proinflammatory priming, and cognitive impairment. This pattern supports a central role for IL1-mediated neuroinflammation as a mechanism for cognitive deficits in obesity and diabetes.
\end{abstract}

Key words: diabetes; hippocampus; inflammation; microglia; obesity; synapse

\section{Introduction}

Diabetes and obesity promote chronic inflammation (Odegaard and Chawla, 2013) and compromise the integrity of the blood-brain barrier (Kanoski et al., 2010). Therefore, changes in peripheral cytokine levels have the potential to penetrate the cerebrovasculature and impair synaptic function. This issue is especially pertinent in the context of an aging population because of the increased prevalence of cognitive decline with obesity and insulin resistance (Xu et al., 2010). Reciprocal interactions between immune cells and adipose tissue could create a self-propagating loop in which inflammatory cytokines suppress neuronal function in the hip-

Received Oct. 1, 2013; revised Jan. 2, 2014; accepted Jan. 8, 2014.

Author contributions: J.R.E., M.W.-K., C.L.D., N.K.P., and A.M.S. designed research; J.R.E., M.W.-K., A.D., S.H., C.L.D., N.K.P., and A.M.S. performed research; J.R.E., M.W.-K., A.D., S.H., C.L.D., N.K.P., and A.M.S. analyzed data; J.R.E., M.W.-K., A.D., S.H., C.L.D., N.K.P., and A.M.S. wrote the paper.

This project was supported by an intramural grant from the Medical College of Georgia (C.L.D., N.K.P.) and Grant 1K01DK100616-01 from the National Institute of Diabetes, Digestive, and Kidney Diseases of the NIH (A.M.S.). We are grateful to Dr. Matthew Frank and Dr. Steven Maier for initial training and valuable advice on the microglia isolation protocol, Dr. Ruth Harris for advice on lipectomy and fat transplantation, and Dr. Lynnette McCluskey for critical reading of this manuscript.

The authors declare no competing financial interests.

*J.R.E. and M.W.-K. contributed equally to this work.

Correspondence should be addressed to Alexis M. Stranahan, Medical College of Georgia, Georgia Regents University, Physiology Department, 1120 15th Street, Room CA3145, Augusta, GA 30912. E-mail: astranahan@gru.edu. DOI:10.1523/JNEUROSCI.4200-13.2014

Copyright $\odot 2014$ the authors $\quad 0270-6474 / 14 / 342618-14 \$ 15.00 / 0$ pocampus, thereby altering meal patterns in a manner leading to deposition of more adipose tissue (Henderson et al., 2013). Although the relationship between obesity and inflammation has received extensive support across human and animal studies (for review, see Kanneganti and Dixit, 2012), the existence of such a positive feedback loop remains speculative.

Although the relationship between obesity-induced inflammation and neuronal synaptic function is rapidly gaining attention in the hypothalamus (Wisse and Schwartz, 2009), the consequences of inflammation extend to other brain regions. Emerging evidence indicates that neural systems involved in cognition and memory are also negatively affected in obesity (Stranahan and Mattson, 2012). Numerous mechanisms for behavioral impairment have been proposed, including changes in hormones and gut peptides (Fadel et al., 2013), as well as reductions in neurotrophic factor expression (Stranahan et al., 2009). While the evidence is indirect, there is some indication that proinflammatory cytokines may also contribute to the deleterious effects of diabetes and obesity on learning and memory. Although correlational reports exist demonstrating that cognitive impairment and brain inflammation occur side by side in obese mice (Dinel et al., 2011), no studies have manipulated adiposity to determine whether exposure to the immunological effects of obesity is necessary and/or sufficient to induce cognitive dysfunction. 
To address this issue, we reduced adiposity through treadmill training in leptin receptor-deficient $d b / d b$ mice. This intervention reduced central and adipose inflammation and reversed cognitive and synaptic plasticity deficits among hippocampal neurons. To selectively manipulate adipose tissue, we next used surgical lipectomy of $d b / d b$ mice, with fat transplantation into wild-type (WT) mice. These studies revealed that reducing body fat attenuates neuroinflammation and synaptic dysfunction in $d b / d b$ mice, and fat transplantation evokes central inflammation and neurocognitive impairment in WT mice. Levels of the proinflammatory cytokine interleukin $1 \beta$ (IL1 $\beta$ ) emerged as a correlate for adiposity and cognitive impairment in both of the preceding studies, so we next administered an IL1 receptor antagonist (IL1ra) directly into the hippocampus. This approach demonstrated that reducing neuroinflammation reverses cognitive and synaptic deficits in $d b / d b$ mice and implicates $\operatorname{IL} 1 \beta$ as a mediator of hippocampal dysfunction in obesity.

\section{Materials and Methods}

Animals and exercise protocol. Male homozygous leptin receptor mutant mice $(d b / d b)$ on the C57BL/6/J background were purchased from The Jackson Laboratory with C57BL/6/J (WT) controls at 5 weeks of age. $d b / d b$ mice on the C57BL/6/J background (strain \#000697) have a normal lifespan of $\sim 20$ months (Coleman, 1978). Mice were group housed and allowed to acclimate to the facility for 1 week before being exposed to the treadmill apparatus for a $15 \mathrm{~min}$ habituation session under red light illumination, every day for 1 week between the hours of 7:00 P.M. and 9:00 P.M. (lights on at 7:00 A.M.). Sedentary (SED) mice continued their exposure to an immobile treadmill environment every evening throughout the duration of the experiment, whereas treadmill-trained (TT) mice initially began training on a moving belt at $5 \%$ incline. The first week involved $30 \mathrm{~min}$ of training at $8 \mathrm{~m} / \mathrm{min}$, again beginning at the onset of the active phase (7:00 P.M.). Mice were motivated to run based on avoidance of compressed air, delivered at 50 psi to mice that failed to run on the moving belt. An equivalent number of air puffs was delivered to SED mice during exposure to the immobile treadmill apparatus. After the first week of training, the belt was set at $12 \mathrm{~m} / \mathrm{min}$ and $5 \%$ incline and maintained thereafter during each 45 min training session. This amount of running was calibrated to recapitulate and maintain the activity levels normally exhibited by 5 -week-old $d b / d b$ mice in a running wheel (Stranahan et al., 2009).

Behavioral testing. Behavior testing took place after 10 weeks of treadmill training. Test sessions took place after the treadmill training session under red light illumination. Spatial recognition memory testing in the Y-maze involved an initial $10 \mathrm{~min}$ habituation phase during which the mouse was confined to the start arm of the maze. After habituation, a guillotine door was lifted, and the mouse was permitted to explore until it had fully entered one of the choice arms. After a complete arm entry, the mouse was again confined to the start arm for a 1 min intertrial interval before the next choice. This sequence was repeated five times, and the number of correct alternations was recorded and expressed relative to the number of trials for statistical analysis. Novel-object preference testing took place as described previously (Stranahan et al., 2008a), with the exception that the exploratory intervals were timed on videos played at half speed using JWatcher, a freely available application (http://www.jwatcher.ucla.edu). Each trial lasted for $5 \mathrm{~min}$, with exploration defined as time spent with the nose oriented toward and within 3 $\mathrm{cm}$ of the object during the first minute of the recording.

Surgical treatments. For lipectomy and fat transplantation experiments, mice were anesthetized with isoflurane and given a preemptive dose of buprenorphine $(0.03 \mathrm{mg} / \mathrm{kg}$, s.c.) to alleviate postoperative distress. Bilateral incisions were made through the dermis and muscle superficial to the epididymal fat pads, which were manipulated without excision for sham-operated mice or bilaterally removed for lipectomized (LPX) mice. The excised fat was trimmed into a $500 \mathrm{mg}$ slice and maintained in sterile saline for $<5$ min before insertion into the peritoneal cavity of the recipient mouse. The transplant was secured to the perito- neal muscle with a dissolvable suture before closure and postoperative recovery (Harris et al., 2002; Rooks et al., 2004).

For intrahippocampal delivery of recombinant IL1ra (Kineret; Sobi), mice were anesthetized with isoflurane and implanted with bilateral cannulae (Plastics One) at the following coordinates: anteroposterior, 2.1 $\mathrm{mm}$; mediolateral, \pm 1.5 ; dorsoventral, $2.1 \mathrm{~mm}$. Each side of the bilateral cannula was individually connected to an Alzet minipump (Durect Corporation) for delivery of IL1ra into the hippocampal parenchyma. Recombinant human IL1 ra was delivered at $5 \mathrm{mg} / \mathrm{h}$ for 2 weeks (Barrientos et al., 2003), with artificial CSF (ACSF) as the vehicle. Cannula placements were verified histologically, and delivery of IL1ra was confirmed through measurement of hippocampal IL1ra by ELISA (R\&D Systems).

Mononuclear cell isolation and ex vivo stimulation. Mononuclear cells were isolated from the forebrain via Percoll density gradient as described previously (Frank et al., 2006), with exceptions. In brief, mice were quickly perfused with Dulbecco's PBS (dPBS). The forebrain was rapidly dissected and homogenized in $\mathrm{APBS}$ with $0.2 \%$ glucose using a Ten Broeck manual tissue grinder. The homogenates were passed through a $40 \mu \mathrm{m}$ cell strainer (BD Biosciences) and centrifuged briefly, and the supernatants were removed and discarded. The pellet was resuspended in $70 \%$ isotonic Percoll, and an additional layer of $30 \%$ isotonic Percoll was applied, followed by a layer of $1 \times \mathrm{dPBS}$. The resulting gradient was centrifuged, and the 70\%/30\% interface was collected. After washing off residual Percoll, the cells were counted using a Scepter instrument (Millipore) and plated at 10,000 cells per well in Covance conical-bottom 96-well plates. Each well was exposed to varying concentrations of lipopolysaccharide (LPS; Sigma-Aldrich) diluted in DMEM with 10\% heatinactivated fetal bovine serum (Invitrogen). Plates were maintained in an incubator at $37^{\circ} \mathrm{C}$ under $5 \% \mathrm{CO}_{2}$ for $16-18 \mathrm{~h}$ before collecting media samples, which were stored at $-80^{\circ} \mathrm{C}$ before measurement of IL1 $\beta$ levels. After media collection, cell viability was assessed using the R\&D Systems XTT assay kit. The optical density of the XTT reagent was determined using a plate reader, and all values were normalized to the control well that received no LPS stimulation. The purity of the cell preparation was routinely assessed by immunostaining for ionized calcium binding adapter molecule-1 (IBA1; expressed in $\sim 95 \%$ of isolated cells; Fig. $2 E$ ) and GFAP (expressed in $<1 \%$ of isolated cells; Fig. $2 E$ ).

Hippocampal slice physiology and 1,1'-dioctadecyl-3,3,3' $3^{\prime}$-tetramethylindocarbocyanine perchlorate labeling. Hippocampal slices were prepared for electrophysiology as described previously (Stranahan et al., 2008a). In brief, mice were rapidly decapitated under light isoflurane anesthesia for slice preparation by vibratome sectioning (Leica). After a $1 \mathrm{~h}$ recovery, medial perforant path synapses were functionally identified by the presence of paired pulse depression, and an input-output curve was generated to set stimulation intensity at $50 \%$ of maximal response. A $10 \mathrm{~min}$ baseline recording at $0.05 \mathrm{~Hz}$ was then generated before delivery of a $1 \mathrm{~s}$, $100 \mathrm{~Hz}$ tetanic stimulation to induce long-term potentiation (LTP), quantified based on the percentage increase in the field EPSP (fEPSP) during the last $10 \mathrm{~min}$ of the recording.

A set of slices from each mouse in the LTP experiments was processed for visualization of dendritic spines via juxtacellular labeling with the carbocyanine dye 1,1'-dioctadecyl-3,3,3'3'-tetramethylindocarbocyanine perchlorate (DiI; Invitrogen), as described previously (Wosiski-Kuhn and Stranahan, 2012). Slices were incubated with appropriately placed DiI crystals for $48-72 \mathrm{~h}$ before being mounted on slides, coverslipped in $0.1 \mathrm{M}$ Tris buffer, and imaged that same day on a Zeiss LSM 510 Meta confocal microscope. The red signal corresponding to the emission wavelength for DiI was converted to green for ease of presentation, and secondary or tertiary dendritic segments were imaged to generate five segments per cell, with five cells per animal averaged to produce a single spine density measurement for each subject. An additional subset of acute slices from mice in the lipectomy experiments was prepared for in vitro assessment of hippocampal leptin sensitivity. Leptin (125 nm in ACSF) or vehicle (ACSF) was applied to the slices for $1 \mathrm{~h}$. The hippocampus was then excised from the slices and frozen at $-80^{\circ} \mathrm{C}$ before protein extraction and quantification by Western blotting.

Histology, immunohistochemistry, and immunofluorescence. Epididymal, inguinal, interscapular, and retroperitoneal fat depots were collected from each mouse and weighed, and the epididymal fat pads were fixed in Formalin for paraffin sectioning and histological analysis. Rou- 
tine staining methods were used for hematoxylin staining. Analysis of cell death by TUNEL staining involved proteinase $\mathrm{K}$ unmasking, followed by $\mathrm{H}_{2} \mathrm{O}_{2}$ treatment to block endogenous peroxidase activity. Slides were then preincubated in terminal transferase reaction buffer containing 25 mu Tris- $\mathrm{HCl}, 200 \mathrm{~mm}$ sodium cacodylate, $1 \mathrm{~mm}$ cobalt chloride, and 0.25 $\mathrm{mg} / \mathrm{ml}$ bovine serum albumin and then moved into the same reaction buffer containing biotin-labeled 16-dUTP (Roche). This incubation was performed for $2 \mathrm{~h}$ at $37^{\circ} \mathrm{C}$, followed by incubation in stop wash buffer containing $300 \mathrm{~mm} \mathrm{NaCl}$ and $30 \mathrm{~mm}$ sodium citrate. Subsequent amplification was conducted using the avidin-biotin method (Vector Laboratories) before visualization with diaminobenzadine (DAB). Transplant rejection was determined based on widespread TUNEL in the transplant $(n=2)$, and WT mice were excluded based on this criterion.

Hippocampal immunolabeling for IBA1 (Wako Pure Chemicals), CD163 (Santa Cruz Biotechnology) and major histocompatibility class II protein (MHCII; AbD Serotec) was performed using both peroxidase and fluorescence detection. For immunoperoxidase detection, freefloating sections were quenched in $0.3 \% \mathrm{H}_{2} \mathrm{O}_{2}$ in PBS and then blocked in $5 \%$ normal goat serum or $5 \%$ normal horse serum diluted in PBS with $0.25 \%$ Tween 20 . The rabbit polyclonal antibody against IBA1 was used at 1:1000, rabbit anti-CD163 was applied at 1:200, and the mouse monoclonal antibody against MHCII was used at 1:500, and all primary antibodies were diluted in PBS with $0.25 \%$ Tween 20 . Bound primary antibodies were detected using biotinylated secondary antibodies (Vector Laboratories), amplified using the $\mathrm{ABC}$ method, and chromated with DAB. For fluorescence detection of MHCII and IBA1 or CD163, freefloating sections were quenched in $1 \%$ sodium borohydride before blocking in normal sera and overnight incubation with primary antibodies. The following day, sections were washed, and the bound primary antibody was detected with Alexa Fluor-conjugated secondary antibodies raised against the appropriate species. We also visualized synaptophy$\sin$ (Santa Cruz Biotechnology) and spinophilin (Millipore), as described previously (Stranahan et al., 2011). The staining was visualized on a Zeiss LSM 510 Meta confocal microscope.

The specificity of the synaptophysin antibody used in the current report was demonstrated in a previously published study, based on the absence of labeling in tissue sections from synaptophysin knock-out mice (Stranahan et al., 2011). The peptide immunogen for production of the spinophilin antibody is identical to the sequence used in the initial functional characterization of the spinophilin/neurabin II protein by Allen et al. (1997). Antibodies against this sequence were further validated in tissue from spinophilin knock-out mice (Feng et al., 2000). Staining controls were run for each reaction and involved omission of primary antibodies, and sections processed in this manner reliably and routinely yielded no fluorescent signal.

Unbiased stereological quantification of hippocampal microglia and macrophages. Systematic random sampling was applied to quantify numbers of cells expressing IBA1 (expressed by microglia and macrophages) or CD163 (expressed by perivascular macrophages) in the dentate gyrus using the optical fractionator with the aid of StereoInvestigator software (MicroBrightField). The $x-y$ step size was $200 \mu \mathrm{m}$, and the dissector height was $10 \mu \mathrm{m}$ with a $1.5 \mu \mathrm{m}$ guard zone. Every sixth section throughout the rostrocaudal extent of the hippocampus was sampled for each animal to generate total numbers of IBA1- or CD163-positive cells for the dentate granule cell layer and molecular layer. Coefficients of error (Gundersen, $m=1$ ) were always $<0.10$.

ELISA and Western blotting. ELISAs were performed for measurement of IL1 $\beta$ in media after ex vivo stimulation of isolated cells and in wholecell protein extracts from the hippocampus and epididymal fat pads, using the R\&D Systems ELISA kit according to the instructions of the manufacturer. Serum leptin levels were quantified using an ELISA kit from Millipore (formerly Linco) according to the instructions of the manufacturer and as described previously (Stranahan et al., 2009). For mice in the IL1ra experiments, levels of hippocampal IL1ra were also quantified using an R\&D Systems ELISA kit. Cell lysis and protein extraction were performed as described previously (Stranahan et al., 2008b). Densitometric values derived from the ELISA were normalized to total protein in each sample when appropriate, which was determined using the Bradford assay (Bio-Rad). The Bradford method was also used to load equal amounts ( $50 \mu \mathrm{g} /$ lane) of protein for gel electrophoresis and Western blotting. Antibodies used for protein detection included postsynaptic density 95 (PSD95) (Pierce), synaptophysin (Santa Cruz Biotechnology), spinophilin (Millipore), MHCII (AbD Serotec), MHCI (clone OX18; BD Bioscience), F4/80 (Santa Cruz Biotechnology), CD163 (Santa Cruz Biotechnology), pY705STAT3 (Cell Signaling Technology), total STAT3 (Cell Signaling Technology), and $\beta$-actin (Sigma-Aldrich). Bands were visualized on a chemiluminescence imager, and signals were quantified using NIH ImageJ.

Statistics. Exercise effects on spine density, LTP, Y-maze performance, and synaptic marker expression in $d b / d b$ and WT mice were compared using $2 \times 2$ ANOVA, whereas analysis of object-recognition memory at various time points used $2 \times 2$ repeated-measures ANOVA. Lipectomy and fat transplantation effects on synaptic endpoints were assessed using one-way ANOVA with Bonferroni's post hoc test. Lipectomy and fat transplantation effects on spatial recognition memory were also assessed using one-way ANOVA, whereas analysis of object-recognition memory used a one-way repeated-measures ANOVA design. IL1 ra effects on cognitive and synaptic endpoints in $d b / d b$ and WT mice were assessed using $2 \times 2$ ANOVA, again with the exception that analysis of objectrecognition memory at multiple time points used a $2 \times 2$ repeatedmeasures design. For the treadmill and IL1ra experiments, the response of isolated mononuclear cells to various doses of LPS were analyzed using separate $2 \times 2$ repeated-measures ANOVAs. For isolated mononuclear cells in the lipectomy experiments, the response to LPS stimulation was assessed using one-way repeated-measures ANOVA. Post hoc testing used Bonferroni's-corrected $t$ statistics conducted for each endpoint or each time point, as appropriate. Statistical significance was set at $p<$ 0.05 , and analyses were performed in GraphPad Prism version 4.0 (GraphPad Software) or, in the case of repeated measures, PASW Statistics version 18.0.

\section{Results}

Treadmill training normalizes cognitive and synaptic plasticity in $d b / d b$ mice

$d b / d b$ mice exhibit behavioral impairment on tasks that recruit the hippocampus and associated cortical structures (Stranahan et al., 2008a). To determine the extent to which increasing physical activity attenuates the cognitive phenotype of $d b / d b$ mice, we analyzed hippocampus-dependent memory after 3 months of treadmill training (Fig. 1A). Consistent with previous observations in the Morris water maze paradigm (Stranahan et al., 2008a), SED $d b / d b$ mice exhibit functional deficits across tests of spatial recognition (Fig. $1 B$ ) and object-recognition memory (Fig. 1C). However, TT $d b / d b$ mice performed at levels that were indistinguishable from WT mice, suggesting that increasing physical activity counteracts cognitive impairment in this model (for the Y-maze, $F_{(1,20)}=7.58, p=0.01$, post hoc Bonferroni'scorrected $t$ test, SED WT vs SED $d b / d b t_{(9)}=4.23, p=0.001$, all other comparisons not significant; for the novel-object preference test, $F_{(3,18)}=6.52, p=0.007$, post hoc Bonferroni'scorrected $t$ test, SED WT vs SED $d b / d b, t_{(11)}=4.64, p=0.02$, all other comparisons not significant). The total amount of exploration exhibited by mice in the object-recognition test was comparable across groups, making it unlikely that our results were confounded by differences in motor activity (percentage exploration of both objects, mean \pm SEM, SED WT $=12.48 \pm 1.41$, TT WT $=9.36 \pm 1.15$, SED $d b / d b=10.48 \pm 2.29$, TT $d b / d b=$ $11.61 \pm 1.43)$. This behavioral pattern suggests that treadmill training normalizes hippocampal function in $d b / d b$ mice.

Hippocampal LTP models the changes in synaptic physiology that are thought to occur during learning and memory. We measured LTP at medial perforant path synapses on dentate gyrus granule neurons to evaluate whether treadmill training in $d b / d b$ mice reinstates synaptic plasticity at the primary point of entry for cortical afferents to the hippocampus. Recordings were made 
A

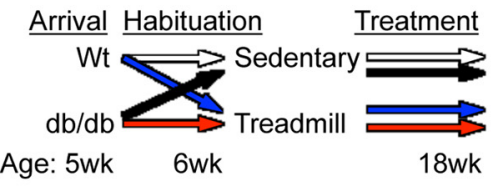

D

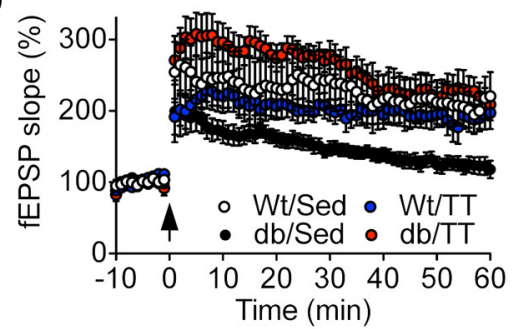

B
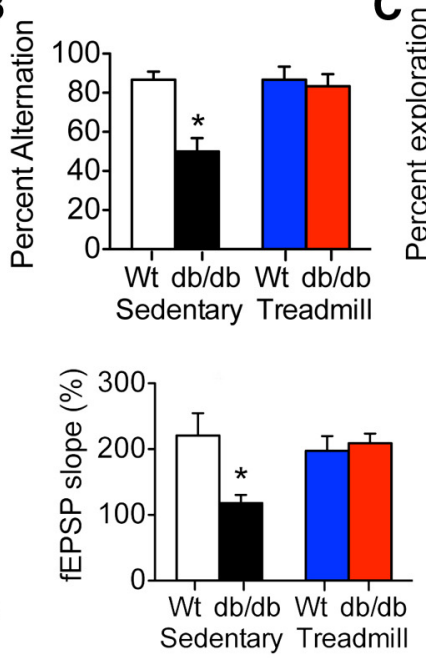

$\mathbf{C}_{\text {. }}$

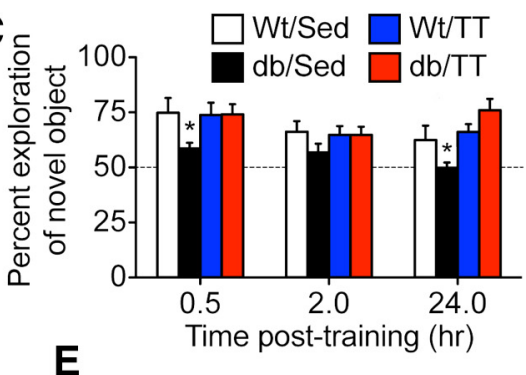

E

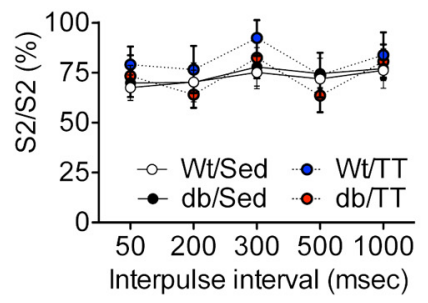

$\mathbf{F}$

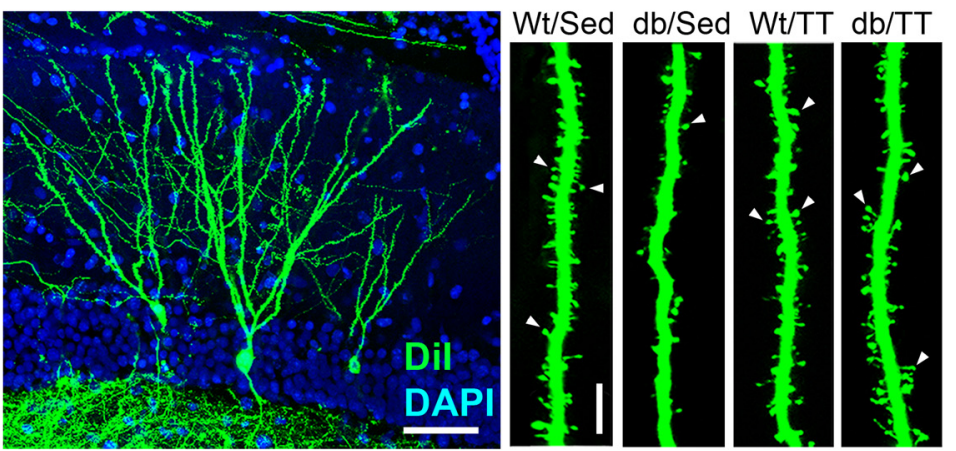

G
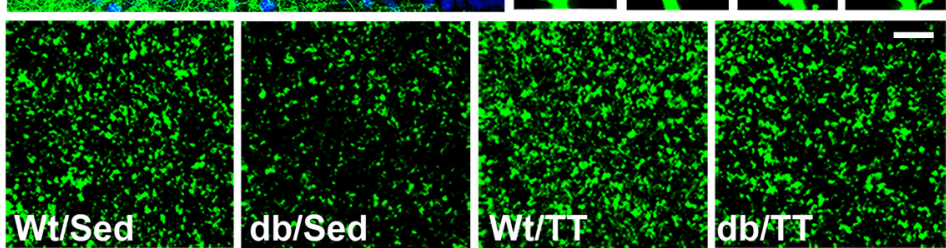

H
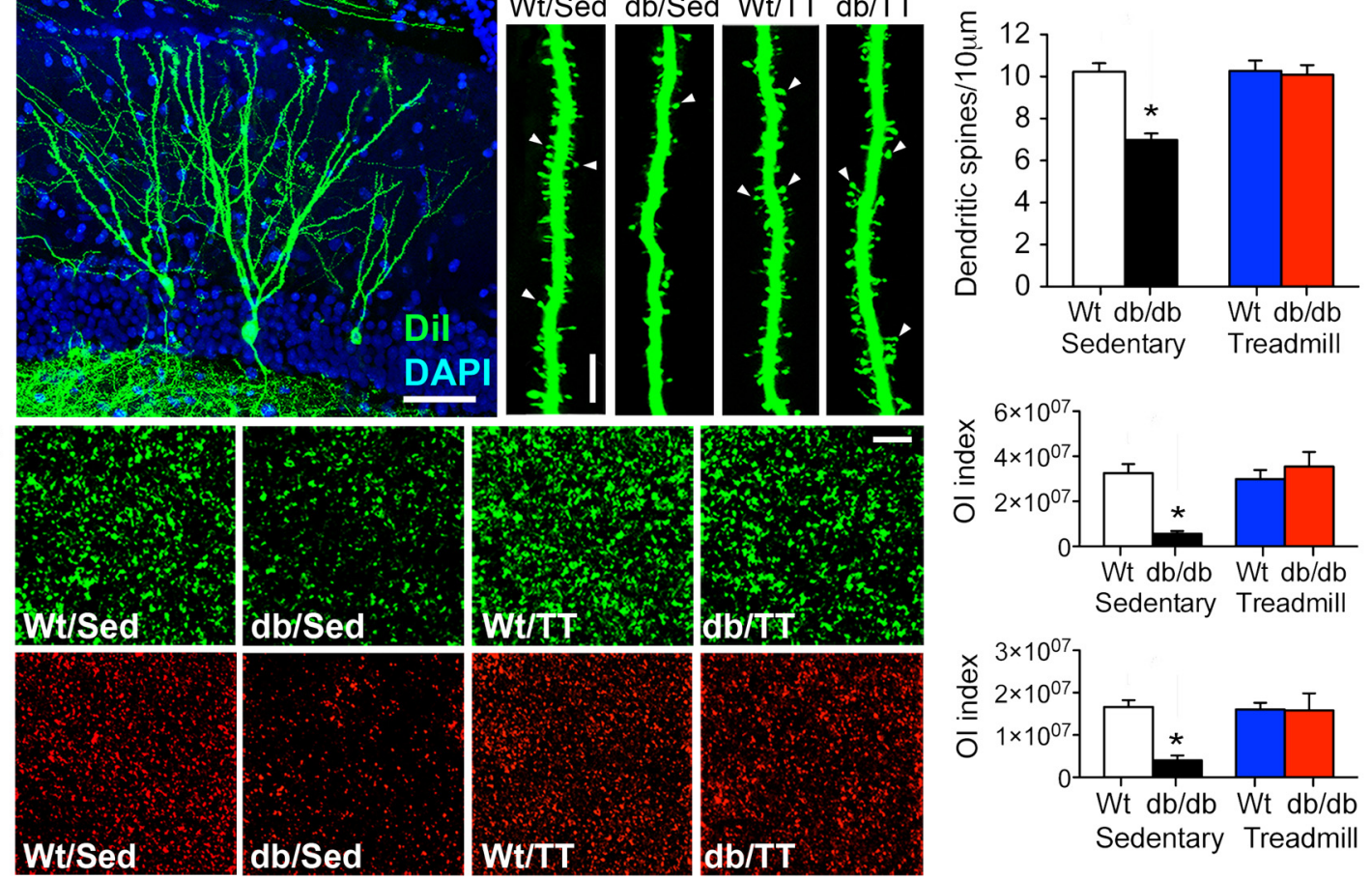

I Condition: Sedentary Treadmill Sedentary Treadmill

Genotype: $W t \mathrm{db} / \mathrm{db}$ Wt db/db Wt db/db Wt db/db
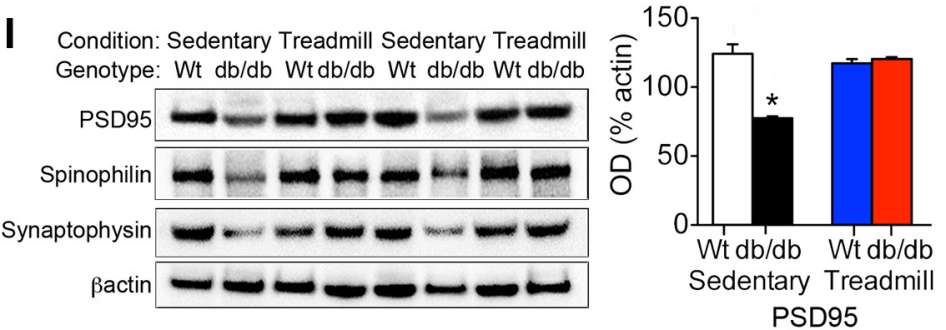

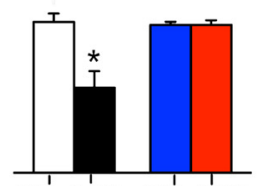

$W t d b / d b \quad W t d b / d b$ Sedentary Treadmil

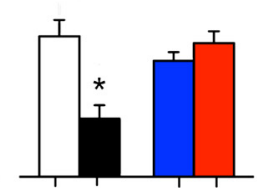

Wt db/db Wt db/db Spinophilin
Synaptophysin

Figure 1. Treadmill training reverses behavioral and synaptic deficits in $d b / d b$ mice. $\boldsymbol{A}$, Experimental design. $\boldsymbol{B}$, Three months of treadmill training normalizes spatial recognition memory as assessed using the Y-maze in $d b / d b$ mice. $C$, Increasing physical activity reinstates object-recognition memory. $\boldsymbol{D}$, Impairment of dentate gyrus LTP in $d b / d b$ mice is abolished by treadmill training. Right graph shows the percentage increase in the slope of the fEPSP during the last $10 \mathrm{~min}$ of the recording. $\boldsymbol{E}$, Presynaptic paired-pulse depression is unaffected by treadmill training or genotype. $\boldsymbol{F}$, Low-magnification micrograph depicts a dentate gyrus granule cell labeled with the lipophilic membrane tracer Dil (green) against blue counterstained nuclei (DAPI). High-magnification panels depict dendritic segments from the indicated conditions. Graph at the right shows dendritic spine densities for each group, with normalization of spine density deficits among $\mathrm{db} / \mathrm{db}$ mice exposed to treadmill training. Arrows indicate dendritic spines. Scale bar, $5 \mu \mathrm{m}$. G, Synaptophysin immunofluorescence in the middle molecular layer of the dentate gyrus. The graph at the right depicts quantification of staining (intensity $\times$ area), with sparser labeling in SED db/db mice, and reversal by treadmill training. $\boldsymbol{H}$, Spinophilin immunofluorescence in the middle molecular layer, revealing parallel changes in labeling for a postsynaptic marker. The graph at the right shows quantification of labeling. I, Western blotting of synaptic proteins in hippocampal homogenates. The graph at the right shows band intensities normalized to loading control for the indicated groups. For all graphs, ${ }^{*} p<0.05$ relative to WT SED mice after $2 \times 2$ ANOVA or $2 \times 2$ repeated-measures ANOVA when appropriate, with Bonferroni's-corrected post hoc t tests. Error bars represent the SEM. 
in the presence of picrotoxin to silence GABAergic excitation on immature neurons and functionally isolate plasticity among the more numerous mature granule cell population, as described previously (Ge et al., 2006; Stranahan et al., 2008a). This approach revealed that LTP deficits are reversed by treadmill training in $d b / d b$ mice, consistent with our observations at the behavioral level (Fig. $1 D ; F_{(1,27)}=4.44, p=0.04$, post hoc Bonferroni's-corrected $t$ test, SED WT vs SED $d b / d b, t_{(13)}=3.32$, $p=0.01$, all other comparisons not significant). This change is likely to be postsynaptically mediated, because presynaptic paired-pulse plasticity was unaffected by genotype or physical activity (Fig. 1E).

Because most excitatory synapses are made at dendritic spines, we next used the lipophilic membrane tracer DiI to visualize spines on dentate gyrus granule neurons. The cells selected for analysis were located in the middle to superficial portion of the dentate granule cell layer, with dendrites that ascended into the middle and outer molecular layer, indicative of morphological maturity. Dendritic spines were relatively infrequent along secondary and tertiary segments from this cell population in SED $d b / d b$ mice, but treadmill training abolished this deficit (Fig. $1 F$; $F_{(1,31)}=13.38, p=0.009$, post hoc Bonferroni's-corrected $t$ test, SED WT vs SED $d b / d b, t_{(15)}=5.41, p=0.001$, all other comparisons not significant). To verify that these changes were occurring across the larger population of middle molecular layer spines and synapses, we performed immunofluorescence to detect the postsynaptic marker spinophilin and the presynaptic marker synaptophysin. Using an optical intensity index derived from the area and pixel intensity of suprathreshold fluorescence (Stranahan et al., 2008b), we observed sparse labeling for both markers in SED $d b / d b$ mice (Fig. $1 G, H$ ). This deficit was reversed in the TT $d b / d b$ mice (for spinophilin, $F_{(1,22)}=16.62, p=0.005$, post hoc Bonferroni's-corrected $t$ test, SED WT vs SED $d b / d b, t_{(11)}=4.99$, $p=0.01$, all other comparisons not significant; for synaptophysin, $F_{(1,22)}=9.12, p=0.006$, post hoc Bonferroni's-corrected $t$ test, SED WT vs SED $d b / d b, t_{(11)}=4.56, p=0.003$, all other comparisons not significant), strongly suggesting that alterations in spine density reflect widespread changes in synapse number. The immunofluorescence observations were upheld in subsequent Western blot experiments (Fig. 1I), with parallel changes in the expression of the scaffolding protein $\operatorname{PSD} 95\left(F_{(1,8)}=4.37\right.$, $p=0.02$, post hoc Bonferroni's-corrected $t$ test, SED WT vs SED $d b / d b, t_{(5)}=8.45, p=0.001$, all other comparisons not significant), spinophilin $\left(F_{(1,8)}=9.02, p=0.03\right.$, post hoc Bonferroni'scorrected $t$ test, SED WT vs SED $d b / d b, t_{(5)}=4.24, p=0.02$, all other comparisons not significant), and synaptophysin $\left(F_{(1,8)}=\right.$ $5.26, p=0.01$, post hoc Bonferroni's-corrected $t$ test, SED WT vs $\mathrm{SED} d b / d b, t_{(5)}=5.23, p=0.03$, all other comparisons not significant). Together, this pattern of functional and structural alterations indicates that obesity, rather than leptin receptor deficiency per se, negatively affects neuronal functioning in the hippocampus.

\section{Treadmill training inhibits hippocampal and adipose inflammation in $d b / d b$ mice}

Systemic inflammation is a recognized contributor to obesity and insulin resistance in humans and in animal models, including $d b / d b$ mice (O'Connor et al., 2005). Because we observed impaired hippocampal plasticity in $d b / d b$ mice, we examined changes in the number and activation status of hippocampal microglia and macrophages. Microglia and macrophages proliferate in response to injury and inflammation, so we initially used unbiased stereology to quantify the number of cells in the hip- pocampal dentate gyrus that express IBA1. Consistent with the robust systemic inflammation reported previously in this model (O'Connor et al., 2005), SED $d b / d b$ mice had more IBA1-positive cells than WT mice (Fig. 2A). However, treadmill training completely blocked increases in IBA1-positive cell number, suggesting that increased physical activity retains the capacity to reduce inflammation despite leptin receptor insufficiency (Fig. 2A; $F_{(1,25)}=9.95, p=0.004$, post hoc Bonferroni's-corrected $t$ test, SED WT vs SED $d b / d b, t_{(11)}=4.23, p=0.001$, all other comparisons not significant). Subsequently, we used immunoperoxidase detection of MHCII as a marker of activation. Although SED $d b / d b$ mice had widespread MHCII immunoreactivity throughout the hippocampus, this pattern was abolished after 3 months of treadmill training (Fig. 2B). MHCII protein levels were also quantified by Western blotting, which upheld the substantial change in expression of this proinflammatory marker (Fig. $2 B$; $F_{(1,20)}=25.34, p=0.001$, post hoc Bonferroni's-corrected $t$ test, SED WT vs SED $d b / d b, t_{(9)}=2.28, p=0.01$, all other comparisons not significant). Because MHCI has also been implicated recently in the regulation of hippocampal synaptic plasticity (Fourgeaud et al., 2010), we measured MHCI expression, which is constitutive and not as closely correlated with inflammation. No changes in $\mathrm{MHCI}$ expression were detected (Fig. 2B), suggesting that microglia and macrophage activation in $d b / d b$ mice recruits adaptive rather than innate immunological profiles.

By using immunofluorescence to detect IBA1 and MHCII, we observed that MHCII expression among IBA1-positive cells was substantially higher in SED $d b / d b$ mice relative to TT $d b / d b$ mice, suggesting that this cell population exhibits robust induction of proteins associated with chronic inflammation (Fig. 2C; percentage double-labeled, SED WT $=3.47 \pm 0.14$, SED $d b / d b=76.45 \pm 1.02$, TT WT $=5.45 \pm 0.82$, TT $d b / d b=$ $12.56 \pm 2.13)$. Consistent with this observation, levels of IL1 $\beta$, a prominent proinflammatory cytokine known to suppress neuronal synaptic plasticity, are increased in the hippocampus of SED $d b / d b$ mice (Fig. $2 D ; F_{(1,22)}=25.41, p=0.001$ ). Upregulation of IL1 $\beta$ was reversed by treadmill training, indicating that production of a proinflammatory cytokine known to inhibit hippocampal function is attenuated by exercise in a leptin receptor-independent manner (post hoc Bonferroni'scorrected $t$ test, SED WT vs SED $d b / d b, t_{(9)}=2.48, p=0.02$, all other comparisons not significant).

An additional cohort of TT $d b / d b$ and WT mice was generated to isolate and stimulate forebrain mononuclear cells ex vivo. Cell preparations were routinely IBA1 positive, with virtually no expression of the astroglial marker GFAP (Fig. 2E). Just as peritoneal macrophages from $d b / d b$ mice exhibit a lower threshold for synthesis of proinflammatory cytokines after stimulation with LPS (O'Connor et al., 2005), forebrain mononuclear cells from SED $d b / d b$ mice also display a leftward shift in their dose-response relationship, indicative of sensitization (Fig. $2 F$ ). Increasing physical activity blocked sensitization in isolated cells from $d b / d b$ mice, suggesting that the signals that prime microglia and macrophages in $d b / d b$ mice were antagonized by treadmill training $\left(F_{(3,20)}=18.28\right.$, $p=0.001$, post hoc Bonferroni's-corrected test after $10 \mathrm{ng} / \mathrm{ml}$ LPS, $t_{(9)}=3.01=0.02$; post hoc Bonferroni's-corrected test after $100 \mathrm{ng} / \mathrm{ml} \mathrm{LPS,} t_{(9)}=3.41, p=0.01$; post hoc Bonferroni's-corrected test after $1000 \mathrm{ng} / \mathrm{ml} \mathrm{LPS,} t_{(9)}=4.10$, $p=0.005$, all other comparisons not significant). These observations could not be explained by differential viability of the isolated cells, because our cell viability assay revealed no differences across treatment conditions (Fig. $2 F$ ). 

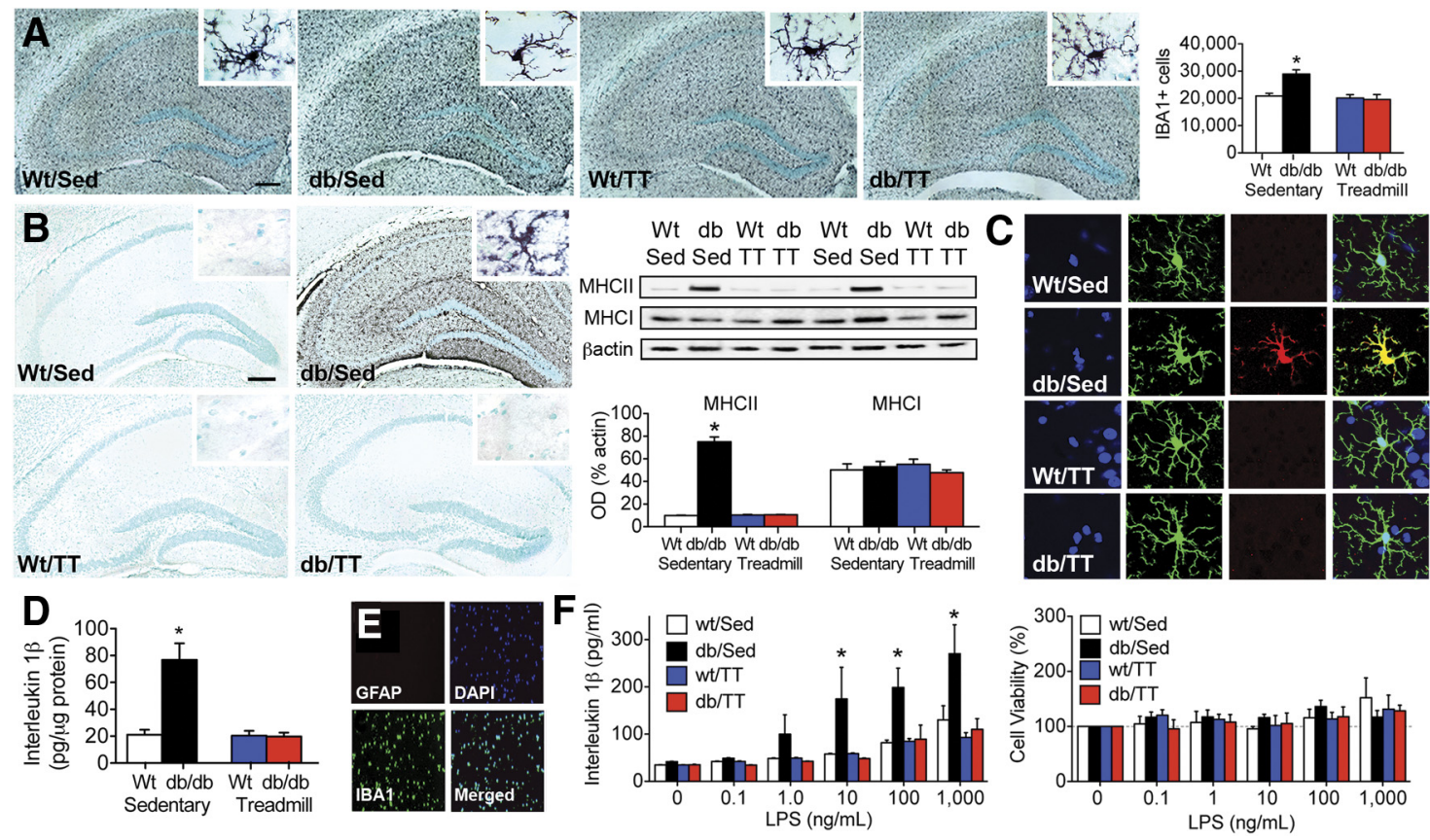

Figure 2. Increasing physical activity reduces hippocampal inflammation in obese mice. A, Microglia and macrophages express MHCII on exposure to inflammatory stimulation. Western blotting of hippocampal homogenates revealed that SED $d b / d b$ mice have more MHCII protein, with no change in the constitutively expressed MHCl. Graph depicts band intensities. ${ }^{*} p<0.05$ by $2 \times 2$ ANOVA. B, Stereological estimates of IBA1-positive cell numbers in the dentate gyrus. C, MHCIl immunoreactivity is widespread in hippocampal sections from SED $d b / d b$ mice but absent in sections from $d b / d b$ mice exposed to 3 months of treadmill training. $D$, Representative micrographs of hippocampal sections used for quantification of IBA1-positive cell numbers. SED $d b / d b$ mice have more IBA1-positive cells than TT $d b / d b$ mice. $\boldsymbol{E}$, We used ELISA to measure levels of the proinflammatory cytokine IL1 $\beta$ in whole-hippocampal homogenates and observed that exercise attenuates increases in IL1 $\beta$ in $d b / d b$ mice. $\boldsymbol{F}$, Mononuclear cells were isolated from $d b / d b$ and WT mice after 3 months of treadmill training or exposure to an immobile belt. Ex vivo stimulation with progressively increasing doses of LPS revealed that cells from SED $d b / d b$ mice are more reactive based on their lower threshold for release of IL $1 \beta$ (left graph). Increased reactivity was abolished by treadmill training and could not be explained by differential survival of the cells (right graph). For $\boldsymbol{F}_{,}{ }^{*} p<0.05$ relative to WT SED mice after $2 \times 2$ repeated-measures ANOVA with significance determined by Bonferroni's-corrected post hoc $t$ tests. Error bars represent the SEM.

Adipose tissue is a haven for macrophages, which are a recognized source of proinflammatory cytokines in obese humans and animal models. To determine whether exercise reduced adiposity in $d b / d b$ mice, we excised and weighed the epididymal, inguinal, retroperitoneal, and interscapular fat pads. Treadmill training only modestly reduced body weight (Fig. $3 A ; F_{(1,20)}=4.66, p=$ 0.001, post hoc Bonferroni's-corrected $t$ test comparing body weight between TT $d b / d b$ mice and SED $d b / d b$ mice after 12 weeks of training, $\left.t_{(9)}=4.01, p=0.007\right)$, but the weight of the epididymal fat pad as a percentage of total body weight was significantly reduced after 3 months of treadmill training in $d b / d b$ mice (Fig. $3 B ; F_{(1,20)}=8.96, p=0.007$; post hoc Bonferroni'scorrected $t$ test, SED WT vs SED $d b / d b, t_{(9)}=7.94, p=0.001$, TT $d b / d b$ vs $\operatorname{SED} d b / d b, t_{(9)}=3.71, p=0.002$, all other comparisons not significant). Reductions in fat pad weight occurred despite comparable hyperphagia in $d b / d b$ mice under SED or TT conditions (grams per $24 \mathrm{~h}$, mean $\pm \mathrm{SEM}$, SED WT $=3.31 \pm 0.22$, TT $\mathrm{WT}=3.36 \pm 0.19, \mathrm{SED} d b / d b=4.08 \pm 0.31, \mathrm{TT} d b / d b=4.48 \pm$ 0.20 ). Because the epididymal depot responded so strongly, subsequent histological and Western blot experiments focused on this fat pad specifically. The area of individual fat cells on histological sections was reduced by treadmill training in $d b / d b$ mice (Fig. $3 C, D ; F_{(1,20)}=39.27, p=0.001$; post hoc Bonferroni'scorrected $t$ test, SED WT vs SED $d b / d b, t_{(9)}=15.48, p=0.0001$, $\mathrm{TT} d b / d b$ vs SED $d b / d b, t_{(9)}=6.97, p=0.001$, all other comparisons not significant), and $\mathrm{F} 4 / 80$-positive macrophages were less frequent (F4/80-positive cells per square micrometer, mean \pm SEM, SED WT $=2.62 \pm 0.28$, SED $d b / d b=9.49 \pm 0.45$, TT $\mathrm{WT}=2.48 \pm 0.58$, TT $d b / d b=5.20 \pm 0.46$ ). To corroborate and extend these histological observations, we performed ELISA and
Western blotting on protein extracts from the epididymal fat pad. Levels of IL1 $\beta$ were significantly higher in epididymal fat from SED $d b / d b$ mice relative to TT $d b / d b$ mice and WT mice (Fig. $3 E$; $F_{(1,41)}=10.11, p=0.002$, post hoc Bonferroni's-corrected $t$ test, SED WT vs SED $d b / d b, t_{(11)}=6.23$, all other comparisons not significant). Moreover, markers of adipose tissue macrophage infiltration and inflammation were elevated in SED $d b / d b$ mice and reduced in TT $d b / d b$ mice (Fig. $3 G$; for F4/80, $F_{(1,8)}=16.87$, $p=0.01$, post hoc Bonferroni's-corrected $t$ test, SED WT vs SED $d b / d b, t_{(5)}=5.92, p=0.001$, all other comparisons not significant; for CD163, $F_{(1,8)}=5.21, p=0.04$, post hoc Bonferroni'scorrected $t$ test, SED WT vs SED $d b / d b, t_{(5)}=2.59, p=0.02$, all other comparisons not significant; for MHCII, $F_{(1,8)}=20.60, p=$ 0.01 , post hoc Bonferroni's-corrected $t$ test, SED WT vs SED $d b /$ $d b, t_{(5)}=7.79, p=0.001$, all other comparisons not significant).

These parallel changes in hippocampus and epididymal fat suggest that some circulating factor might be released from adipose tissue macrophages, with increased exposure to this factor among hippocampal neurons, leading to local inflammation and cognitive impairment. Consistent with this hypothesis, we observed similar alterations in circulating IL1 $\beta$, which was elevated in SED $d b / d b$ mice but comparable with WT in TT $d b / d b$ mice (Fig. 3F; $F_{(1,33)}=14.13, p=0.007$, post hoc Bonferroni'scorrected $t$ test, SED WT vs SED $d b / d b, t_{(14)}=5.65, p=0.002$, all other comparisons not significant). Although IL1 $\beta$ is not the only cytokine known to fluctuate with obesity and diabetes, the consistency that we observed across epididymal fat, serum, and hippocampus opens the possibility of a role for adipose-derived IL1 $\beta$ as a contributor to the relationship between adiposity and hippocampal function. 


\section{Opposite effects of lipectomy and fat transplantation on hippocampal plasticity}

To directly manipulate adiposity, we relied on surgical lipectomy for removal of the epididymal fat pad in $d b / d b$ mice. The excised fat was then transplanted into the peritoneal cavity of a WT mouse to determine whether increasing adiposity in this manner evokes cognitive and synaptic deficits (Fig. 4A). Behavioral analysis of spatial and object-recognition memory revealed that fat transplantation induces cognitive impairment in WT mice and lipectomy reverses cognitive deficits in $d b / d b$ mice (Fig. $4 B, C$; for the Y-maze, $F_{(3,22)}=8.53, p=0.009$, post hoc Bonferroni's-corrected $t$ test, for the effect of fat transplantation in WT, $t_{(11)}=4.48$, $p=0.002$, for the effect of lipectomy in $d b / d b, t_{(11)}=3.96, p=0.001$; for the novel-object preference test, $F_{(3,22)}=$ 24.52, $p=0.001$, post hoc Bonferroni'scorrected $t$ test, for the effect of fat transplantation in WT, $t_{(11)}=5.33, p=0.004$; for the effect of lipectomy in $d b / d b, t_{(11)}=$ $4.38, p=0.002$ ) This pattern could not be explained by differences in motor activity, because the amount of exploratory behavior was comparable across groups (percentage exploration of both objects, mean \pm SEM, sham $\mathrm{WT}=13.54 \pm 1.42$, transplant WT $=17.87 \pm 1.19$, sham $d b /$ $d b=10.73 \pm 1.13, \mathrm{LPX} d b / d b=11.51 \pm$ 1.18).

We next assessed changes in synaptic plasticity by measuring medial perforant path LTP. The opposite effects of lipectomy and fat transplantation observed in this assay parallels our behavioral findings, with reinstatement of LTP after lipectomy in $d b / d b$ mice and induction of LTP deficits after fat transplantation in WT mice (Fig. $4 D ; F_{(3,32)}=8.06, p=$ 0.005 , post hoc Bonferroni's-corrected $t$ test, for the effect of fat transplantation in WT, $t_{(13)}=4.32, p=0.001$, for the effect of lipectomy in $\left.d b / d b, t_{(13)}=3.89, p=0.002\right)$. Changes in LTP were accompanied by similar reduction or reinstatement of dendritic spine density among DiI-labeled dentate gyrus granule cells (Fig. $4 E, F ; F_{(3,22)}=11.55, p=0.002$, post hoc Bonferroni's-corrected $t$ test, for the effect of fat transplantation in WT, $t_{(11)}=5.42, p=$ 0.001 , for the effect of lipectomy in $\left.d b / d b, t_{(11)}=3.86, p=0.004\right)$. Structural changes at the spine were detectable not only among the subset of DiI-labeled cells but also at the level of synaptic marker protein expression in whole-hippocampus homogenate, indicating that lipectomy and fat transplantation induce widespread changes in synaptic connectivity (Fig. 4G-J; for PSD95, $F_{(3,14)}=33.94, p=0.002$, post hoc Bonferroni's-corrected $t$ test, for the effect of fat transplantation in WT, $t_{(7)}=9.75, p=0.001$, for the effect of lipectomy in $d b / d b, t_{(7)}=8.59, p=0.004$; for spinophilin, $F_{(3,14)}=13.41, p=0.002$, post hoc Bonferroni'scorrected $t$ test, for the effect of fat transplantation in WT, $t_{(7)}=$ $14.46, p=0.001$, for the effect of lipectomy in $d b / d b, t_{(7)}=16.61$, $p=0.001$; for synaptophysin, $F_{(3,14)}=20.21, p=0.004$, post hoc Bonferroni's-corrected $t$ test, for the effect of fat transplantation in WT, $t_{(7)}=4.91, p=0.003$, for the effect of lipectomy in $d b / d b$, $\left.t_{(7)}=5.22, p=0.01\right)$.

\section{Lipectomy reverses and fat transplantation promotes} central inflammation

We measured MHCII expression by Western blotting to evaluate whether hippocampal inflammation parallels changes in adiposity after lipectomy or fat transplantation. Sham operation failed to induce hippocampal MHCII protein expression in WT mice, but fat transplantation led to robust increases in this inflammatory marker (Fig. $5 A ; F_{(3,15)}=16.95, p=0.001$, post hoc Bonferroni's-corrected $t$ test, for the effect of fat transplantation in WT, $t_{(7)}=5.67, p=0.009$, for the effect of lipectomy in $\left.d b / d b, t_{(7)}=4.97, p=0.002\right)$. This response was only observed for MHCII, with no change in the protein expression of MHCI based on genotype or surgical treatment (Fig. 5A). To determine the cellular source for MHCII expression, we performed double labeling to detect MHCII and the perivascular macrophage marker CD163 or the macrophage and microglia marker IBA1. Using unbiased stereology, we observed that the number of CD163-positive cells increases after fat transplantation into lean mice and decreases after lipectomy in obese mice (Fig. $5 B, C ; F_{(2,23)}=7.79, p=0.002$, post hoc Bonferroni's-corrected $t$ test, for the effect of fat transplantation in WT, $t_{(11)}=3.84, p=0.01$, for the effect of 
A
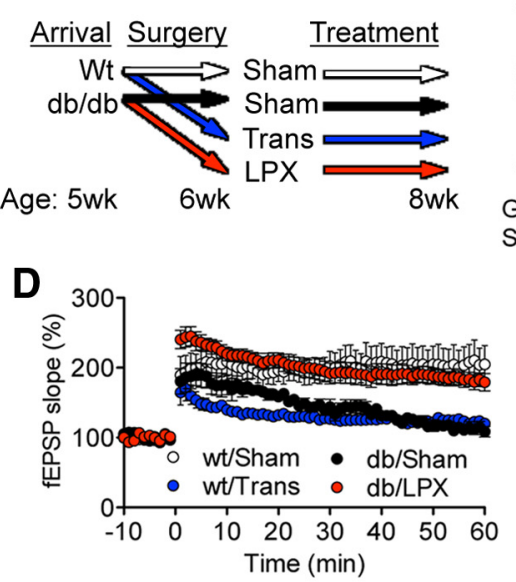

B

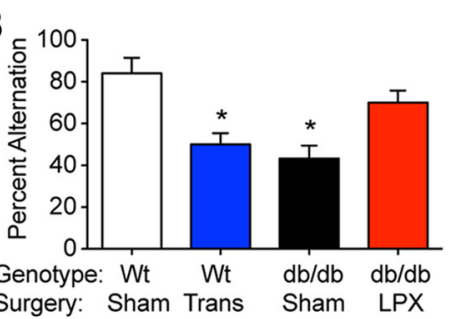

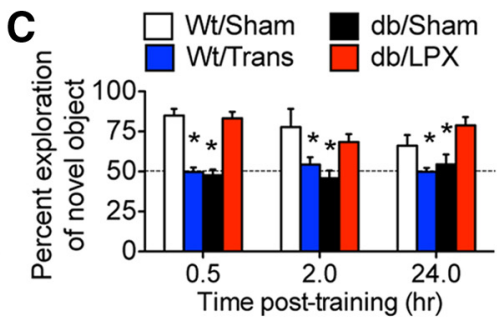

E

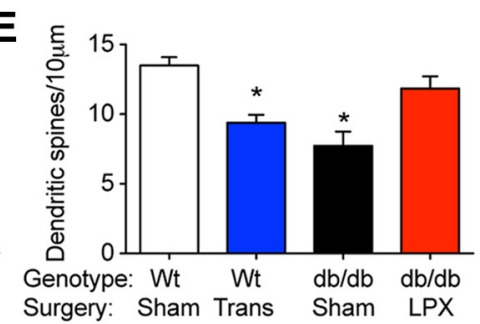

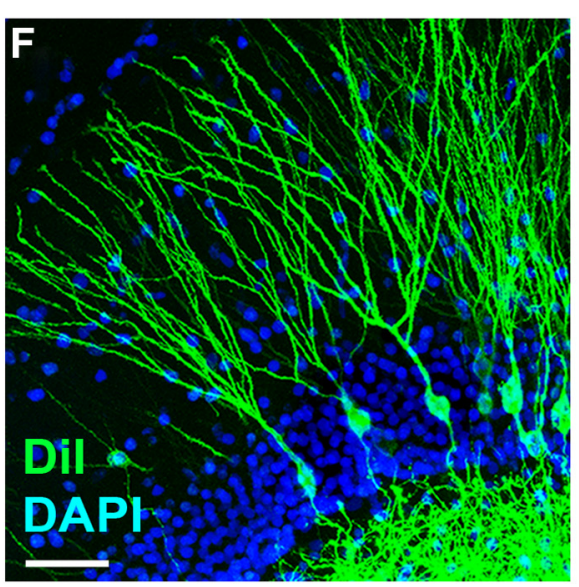

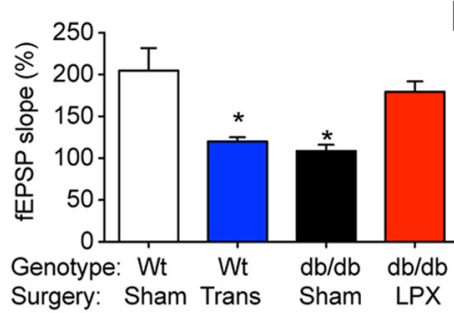

G

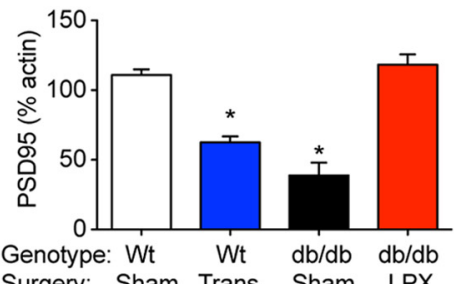

Surgery: Sham Trans Sham LPX

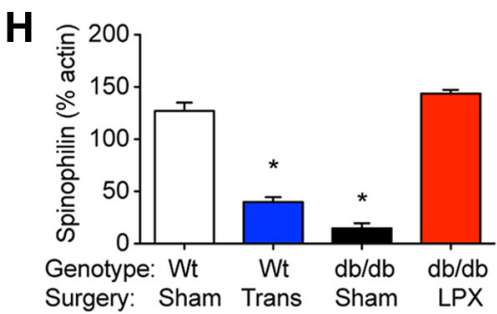

J

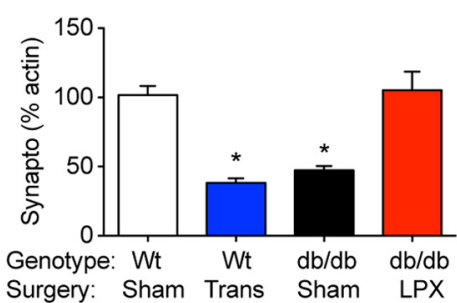

Figure 4. Lipectomy reverses and fat transplantation produces neurocognitive impairment. $\boldsymbol{A}$, Experimental design. Trans, transplant recipient. $\boldsymbol{B}$, Analysis of spatial recognition memory in the Y-maze reveals that surgical removal of epididymal fat reverses impairment in $d b / d b$ mice, whereas transplantation of fat into WT mice evokes deficits. C, Similar trends were observed in the object-recognition memory paradigm, with reinstatement of recognition memory after lipectomy in $d b / d b$ mice and induction of memory impairment after fat transplantation in WT mice. $\boldsymbol{D}$, Dentate gyrus LTP is impaired by fat transplantation in WT mice and restored by lipectomy in $d b / d b$ mice. The right graph shows the percentage increase in the slope of the fEPSP during the last 10 min of the recording. $\boldsymbol{E}$, Quantification of dendritic spine density on dentate granule neurons revealed parallel alterations in spines. $\boldsymbol{F}$, Low-power micrograph depicts Dil-labeled dentate gyrus granule cells, whereas higher-power images at the right show representative segments from each condition. Arrows indicate dendritic spines. Scale bar, $5 \mu \mathrm{m}$. G, Analysis of PSD95 expression in whole-hippocampal homogenates revealed opposite effects of lipectomy and fat transplantation. $\boldsymbol{H}$, Similar trends were observed for spinophilin expression, with impairment elicited by fat transplantation in WT mice, and restoration of this synaptic marker after lipectomy in $\mathrm{db} / \mathrm{db}$ mice. $I$, Representative Western blot images for the indicated markers. $J$, Graph depicts synaptophysin expression for the indicated groups, demonstrating opposite effects of lipectomy and fat transplantation on presynaptic marker expression. For all graphs, ${ }^{*} p<0.05$ relative to sham-operated mice from the respective genotype after $2 \times 2$ ANOVA or $2 \times 2$ repeated-measures ANOVA when appropriate, with Bonferroni's-corrected post hoc $t$ tests. Error bars represent the SEM.

lipectomy in $\left.d b / d b, t_{(11)}=3.92, p=0.008\right)$. The proportion of CD163-positive cells expressing MHCII is also significantly greater in WT mice that receive fat transplants relative to sham-operated WT mice (Fig. $5 B, D$ ); likewise, surgical reduction of body fat through lipectomy attenuates MHCII expression among perivascular macrophages in $d b / d b$ mice (Fig. $5 B, D ; F_{(2,23)}=17.23, p=0.009$, post hoc Bonferroni'scorrected $t$ test, for the effect of fat transplantation in WT, $t_{(11)}=12.39, p=0.004$, for the effect of lipectomy in $d b / d b$, $\left.t_{(11)}=9.59, p=0.002\right)$. The same pattern was observed among the larger population of IBA1-positive cells, which represent microglia and macrophages. Fat transplantation increases and lipectomy reduces IBA1-positive cell accumulation in the hippocampal dentate gyrus (Fig. $5 E, F ; F_{(2,23)}=8.36, p=0.004$, post hoc Bonferroni's-corrected $t$ test, for the effect of fat transplantation in WT, $t_{(11)}=2.55, p=0.005$, for the effect of lipectomy in $\left.d b / d b, t_{(11)}=4.87, p=0.007\right)$, with similar consequences for MHCII expression in this population (Fig. 5G; 
A

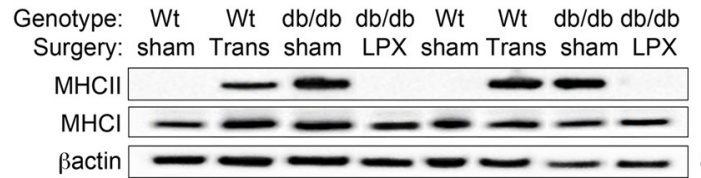

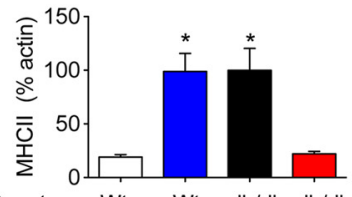

Genotype: Wt Wt $\mathrm{db} / \mathrm{db} \mathrm{db} / \mathrm{db}$ Surgery:Sham Trans Sham LPX

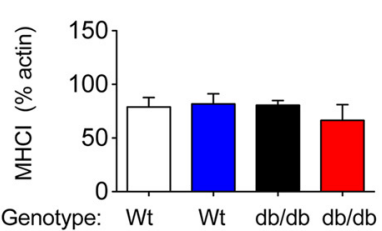

Surgery: Sham Trans Sham LPX
B

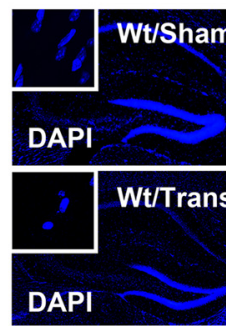

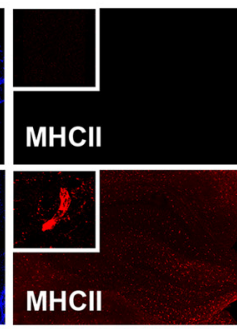
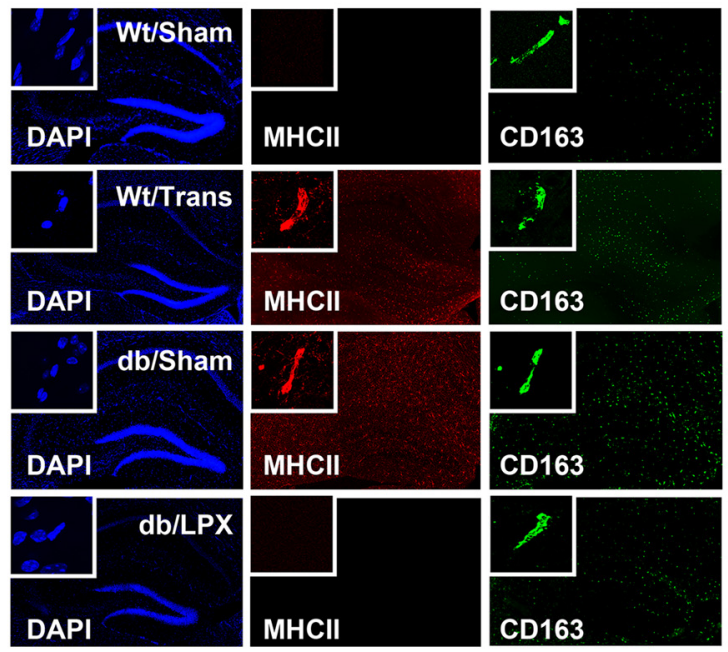

F
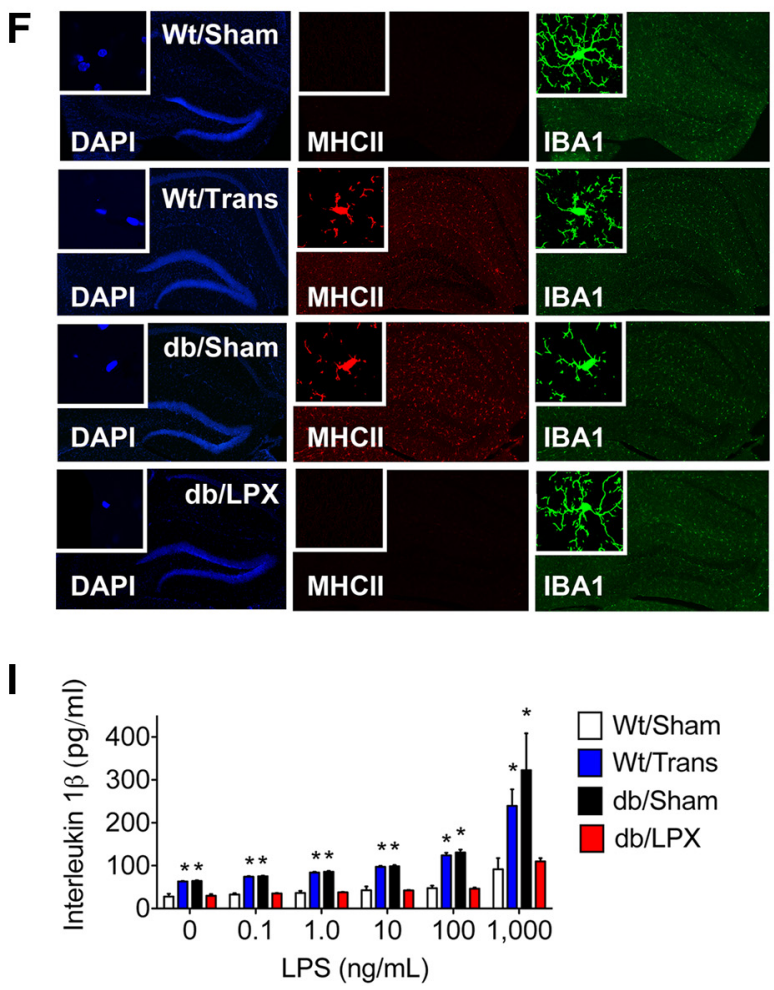
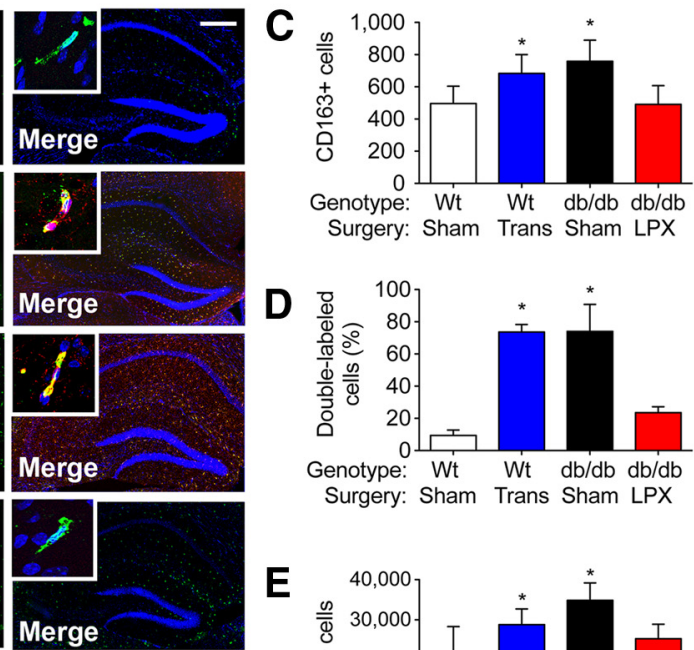

E
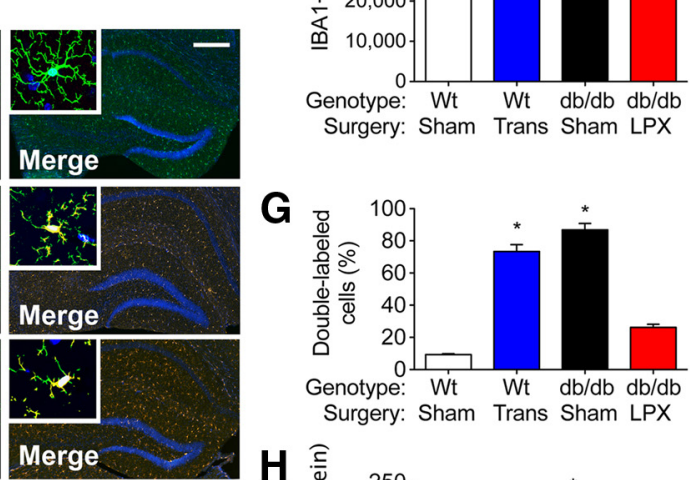

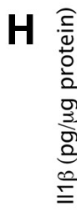
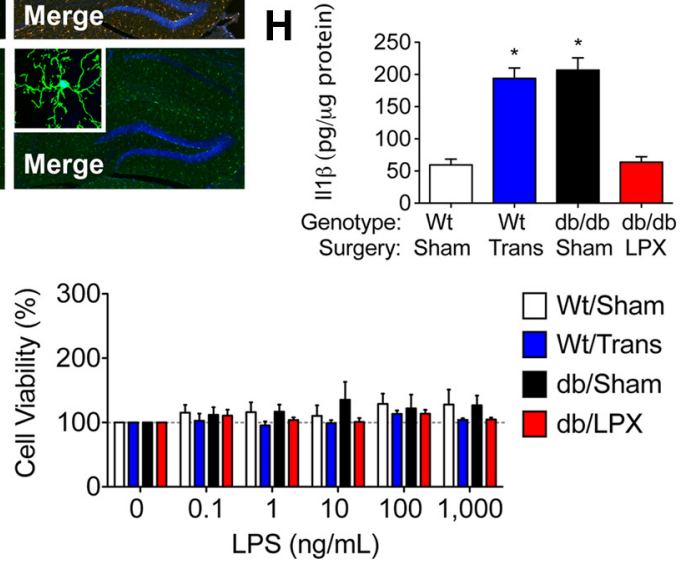

Figure 5. Opposite effects of lipectomy and fat transplantation on hippocampal inflammation in $d b / d b$ and WT mice. $A$, Representative Western blot images for the inflammatory marker MHCII and the constitutively expressed protein $\mathrm{MHCl}$ in the indicated conditions. Quantification of band intensities revealed that fat transplantation elicits and lipectomy reverses the expression of MHCII in whole-hippocampal homogenates (left graph). No alterations in MHCl were detected (right graph). B, Micrographs depict labeling for CD163 and MHCll in each condition. C, The number of cells expressing CD163, a marker of perivascular macrophages, was significantly reduced by lipectomy in $d b / d b$ mice. D, The proportion of CD163 ${ }^{+}$cells expressing MHCll was also far greater in WT mice that received fat transplants and significantly smaller in $\mathrm{db} / \mathrm{db}$ mice after lipectomy. $\boldsymbol{E}$, The number of cells expressing IBA1, a marker of microglia and macrophages, decreases after lipectomy in obese mice. $\boldsymbol{F}$, Micrographs depict immunofluorescent labeling for IBA1 and MHCII. G, This larger population of mixed-lineage immune cells also expresses the inflammatory marker MHCII at higher rates after fat transplantation; obesity-induced $\mathrm{MHCll}$ expression in this population of cells is attenuated by surgical reduction of body fat. $\boldsymbol{H}$, Parallel changes in expression of the proinflammatory cytokine IL1 $\beta$ were observed, with increases after fat transplantation in WT mice and reductions after lipectomy in $d b / d b$ mice. $I$, Fat transplantation primes forebrain mononuclear cells in WT mice, whereas lipectomy attenuates increased reactivity in $d b / d b$ mice after ex vivo stimulation with LPS (left graph). This pattern was not attributable to differences in cell viability (right graph). For all graphs, ${ }^{*} p<0.05$ relative to sham-operated mice from the respective genotype after one-way or repeated-measures ANOVA when appropriate, with Bonferroni's-corrected post hoc $t$ tests. Error bars depict the SEM. 

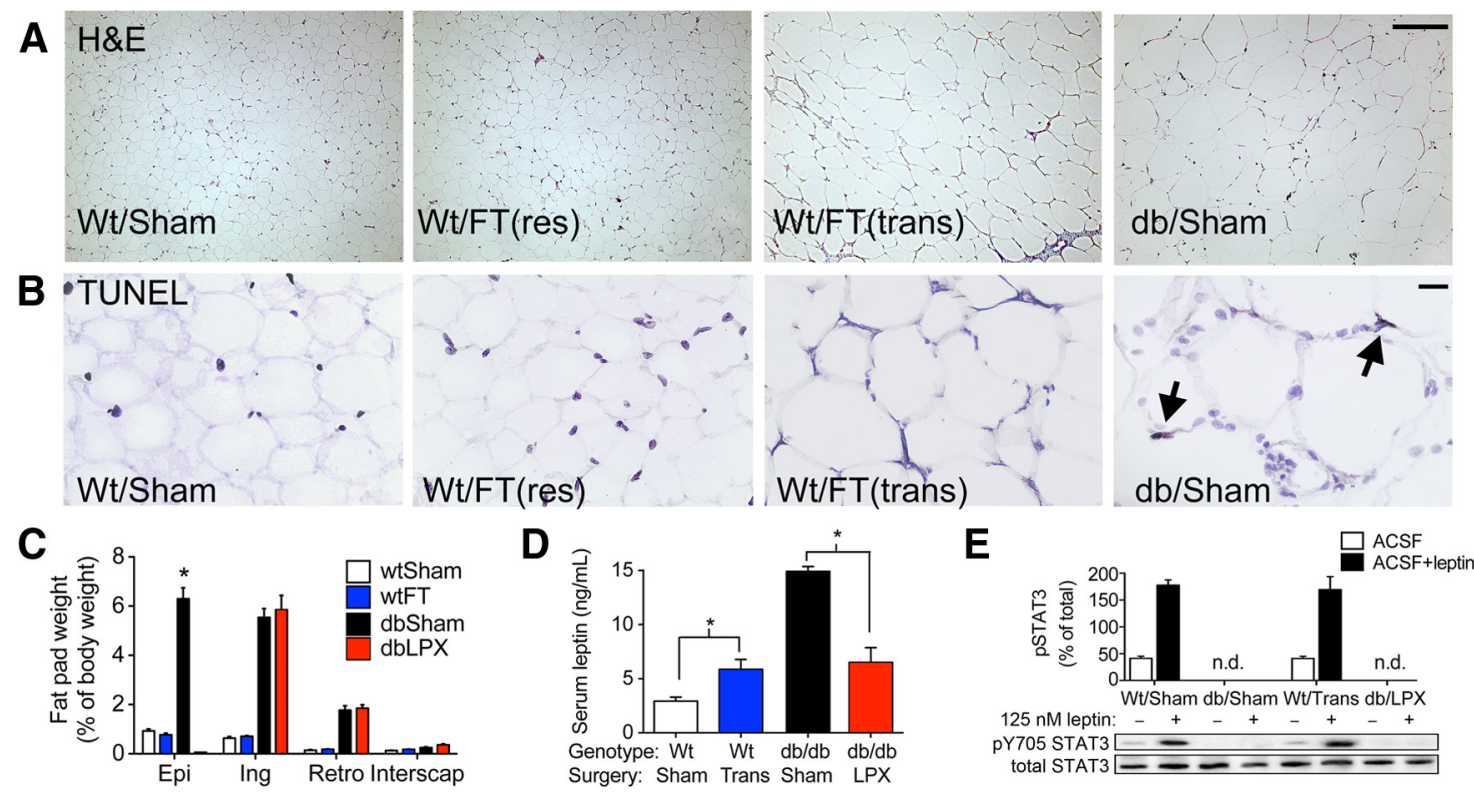

Figure 6. Transplanted fat is viable and transplant recipients exhibit elevated serum leptin without alterations in hippocampal leptin sensitivity. $\boldsymbol{A}$, H\&E staining of epididymal fat from the indicated groups. res, Resident fat; trans, transplanted fat. $\boldsymbol{B}$, Staining for TUNEL in epididymal fat sections from the indicated groups. Arrows indicate TUNEL-positive cells. $\boldsymbol{C}$, Analysis of fat pad weights at 2 weeks after surgery revealed no evidence for compensation in other fat pads. $D$, Serum leptin levels when elevated by fat transplantation in WT mice and reduced by lipectomy in $\mathrm{db} / \mathrm{db}$ mice. $\boldsymbol{E}$, Hippocampal leptin sensitivity is intact after fat transplantation in WT mice based on phosphorylation of STAT3, an intracellular signaling targets of the leptin receptor, after direct application of leptin to hippocampal acute slices. Consistent with their loss-of-function mutation in the long form of the leptin receptor, leptin application did not evoke phosphorylation of STAT3 in $d b / d b$ mice, even after lipectomy. For $\boldsymbol{C}$ and $\boldsymbol{D},{ }^{*} p<0.05$ after one-way ANOVA with Bonferroni's-corrected post hoc $\boldsymbol{t}$ tests. For $\boldsymbol{E}$, ${ }^{*}$ indicates significant effect of leptin treatment in slices generated from mice in each condition. Error bars represent the SEM.

$F_{(2,23)}=14.43, p=0.009$, post hoc Bonferroni's-corrected $t$ test, for the effect of fat transplantation in WT, $t_{(11)}=17.75$, $p=0.001$, for the effect of lipectomy in $d b / d b, t_{(11)}=14.69$, $p=0.003)$. Alterations in MHCII expression were accompanied by parallel changes in hippocampal IL1 $\beta$ (Fig. $5 H$; $F_{(3,39)}=33.56, p=0.001$, post hoc Bonferroni's-corrected $t$ test, for the effect of fat transplantation in WT, $t_{(19)}=17.92$, $p=0.003$, for the effect of lipectomy in $d b / d b, t_{(20)}=22.42$, $p=0.001)$, suggesting that hippocampal microglia and macrophages are activated by a signal emanating from adipose tissue.

An additional set of sham-operated, LPX, or fat transplanted mice was generated for analysis of microglia and macrophage responses to LPS stimulation ex vivo. Isolated mononuclear cells from WT mice that received a fat transplant were significantly more reactive based on their reduced threshold for release of IL1 $\beta$ into the media (Fig. $5 I ; F_{(3,15)}=19.93, p=0.001$; post hoc Bonferroni's-corrected $t$ test comparing IL1 $\beta$ in media from cells isolated from sham-operated WT mice with cells isolated from WT mice receiving fat transplants after stimulation with $10 \mathrm{ng} / \mathrm{ml}$ LPS, $t_{(7)}=2.51, p=0.005$; after stimulation with $100 \mathrm{ng} / \mathrm{ml} \mathrm{LPS}$, $t_{(7)}=2.58, p=0.007$; after stimulation with $1000 \mathrm{ng} / \mathrm{ml} \mathrm{LPS}$, $\left.t_{(7)}=5.24, p=0.003\right)$, whereas lipectomy abolished the sensitization characteristically observed in cells from $d b / d b$ mice (post hoc Bonferroni's-corrected $t$ test comparing IL $1 \beta$ in media from cells isolated from sham-operated $d b / d b$ mice with cells isolated from LPX $d b / d b$ mice after stimulation with $10 \mathrm{ng} / \mathrm{ml} \mathrm{LPS,} t_{(7)}=$ $2.41, p=0.002$; after stimulation with $100 \mathrm{ng} / \mathrm{ml} \mathrm{LPS}, t_{(7)}=2.49$, $p=0.004$; after stimulation with $1000 \mathrm{ng} / \mathrm{ml} \mathrm{LPS}, t_{(7)}=7.54, p=$ $0.009)$. These changes were not attributable to differences in cell viability, because we observed no differences in this parameter across genotypes or surgical conditions (Fig. 5I).
Fat transplantation elevates serum leptin without altering hippocampal leptin sensitivity

We next examined the viability of the transplant by TUNEL and hematoxylin and eosin ( $\mathrm{H} \& \mathrm{E}$ ) staining (Fig. 6A). Although TUNEL-positive adipocytes were occasionally present in epididymal fat from $d b / d b$ mice (Fig. $6 B$ ), the transplanted fat showed very little positive staining, except around the perimeter in which the excised fat was trimmed to generate a $500 \mathrm{mg}$ piece during surgery. Transplants were readily distinguishable from resident fat depots for the following reasons: (1) the peritoneal cavity of WT mice normally contains very little fat, making it easy to locate the transplant placed in the cavity; (2) transplants were routinely anchored to the peritoneal wall with a suture, which remained in place and allowed us to quickly locate the transplanted pad; and (3) the size distribution of adipocytes in the transplant derived from the $d b / d b$ mouse was far greater than the typical area of resident fat cells in WT mice on histological sections (Fig. 6A,B).

Because the remaining fat pads in an LPX $d b / d b$ mouse compensate through hypertrophy and the resident fat pads in WT mice receiving a transplant exhibit some degree of atrophy, we timed our experiments according to previous observations suggesting that compensation begins at $\sim 4$ weeks after transplantation or after lipectomy (Harris et al., 2002; Rooks et al., 2004). At 2 weeks after surgery, the weight of the other fat pads showed no evidence of compensation (Fig. 6C). By taking the total weight of all of the excised fat pads and normalizing to body weight, we validated that lipectomy reduces and fat transplantation increases body fat (mean \pm SEM, sham WT $=1.83 \pm 0.17$, transplantation $\mathrm{WT}=3.29 \pm 0.34$, sham $d b / d b=14.17 \pm 0.66, \mathrm{LPX}$ $d b / d b=7.81 \pm 0.54 ; F_{(3,38)}=10.75, p=0.01$, post hoc Bonferroni's-corrected $t$ test, for the effect of fat transplantation 
in WT, $t_{(19)}=5.37, p=0.007$, for the effect of lipectomy in $d b / d b$, $\left.t_{(19)}=4.18, p=0.001\right)$. There was no evidence of compensation at the level of food intake, because $24 \mathrm{~h}$ intake profiles were comparable across groups (mean \pm SEM, sham WT $=2.94 \pm 0.14$, transplantation $\mathrm{WT}=2.87 \pm 0.36$, sham $\mathrm{db} / \mathrm{db}=4.50 \pm 0.18$, LPX $d b / d b=4.57 \pm 0.13)$. Finally, as an additional measure related to adiposity, we measured serum leptin levels, and consistent with the drastic surgical reduction in body fat, $d b / d b$ mice exhibit lower levels of leptin after lipectomy (Fig. 6D). In support of the viability of the transplants, WT mice that received transplants exhibit increased serum leptin relative to sham-operated WT mice $\left(F_{(3,35)}=8.56, p=0.001\right.$, post hoc Bonferroni'scorrected $t$ test, for the effect of fat transplantation in WT, $t_{(9)}=$ $4.77, p=0.008)$. This pattern is indicative of successful manipulation of adiposity by lipectomy and fat transplantation, because rejection of transplanted fat in WT mice was not accompanied by increases in serum leptin $(n=2$ mice excluded based on widespread TUNEL in the transplanted fat; data not shown). Surgical manipulation of adiposity did not alter hippocampal leptin sensitivity, assessed based on phosphorylation of intracellular signaling targets for the leptin receptor after direct application of leptin to hippocampal slices $\left(F_{(3,16)}=8.54, p=0.001\right.$; Fig. $\left.6 E\right)$.

\section{Intrahippocampal IL1ra infusions reinstate synaptic plasticity}

IL1 $\beta$ emerged as a correlate of adiposity and impaired hippocampal function in both the treadmill and lipectomy studies, so we next infused an IL1 ra into the hippocampus via bilateral cannulae attached to Alzet minipumps (Fig. 7A). Successful intrahippocampal delivery of recombinant IL1ra was verified using ELISA to quantify IL1ra in hippocampal homogenates. Two weeks of IL1ra infusion generated hippocampal levels of IL1ra that were substantially higher than vehicle-infused mice (nanograms per milligrams protein, mean \pm SEM; vehicle-infused $\mathrm{WT}=2.51 \pm 0.59$, vehicle-infused $d b / d b=0.75 \pm 0.06$, IL1 ra $\mathrm{WT}=240.59 \pm 43.35$, IL1 ra $d b / d b=235.75 \pm 36.03)$. To determine how blocking IL receptors using this strategy affects learning and memory, we examined spatial and object-recognition memory using the Y-maze and novel-object preference paradigms. Across both tests, IL1ra infusions completely abolished memory deficits in $d b / d b$ mice (Fig. $7 B, C$; for the Y-maze, $F_{(1,30)}=6.25, p=0.02$, post hoc Bonferroni's-corrected $t$ test, vehicle-infused WT vs vehicle-infused $d b / d b, t_{(9)}=4.89, p=$ 0.001 , all other comparisons not significant; for the novel-object preference test, $F_{(3,19)}=6.05, p=0.004$, post hoc Bonferroni'scorrected $t$ test, vehicle-infused WT vs vehicle-infused $d b / d b$, $t_{(9)}=6.74, p=0.004$, all other comparisons not significant). The proportion of time spent exploring the objects was unaffected by genotype or intrahippocampal IL1ra treatment (percentage time spent exploring both objects, mean \pm SEM, vehicle-infused $\mathrm{WT}=14.56 \pm 1.37, \mathrm{IL} 1 \mathrm{ra} \mathrm{WT}=13.91 \pm 1.36$, vehicle-infused $d b / d b=14.08 \pm 1.47$, IL1 ra $d b / d b=12.81 \pm 1.24)$. To examine synaptic functional plasticity, we again measured LTP at medial perforant path synapses on dentate gyrus granule cells. Intrahippocampal IL1ra infusions normalized LTP in $d b / d b$ mice, without influencing LTP magnitude in WT mice (Fig. $7 D ; F_{(1,36)}=$ $16.39, p=0.003$, post hoc Bonferroni's-corrected $t$ test, vehicleinfused WT vs vehicle-infused $d b / d b, t_{(15)}=5.05, p=0.002$, all other comparisons not significant).

In parallel with these functional assessments, we examined dendritic spine density along the secondary and tertiary dendritic segments of DiI-labeled dentate gyrus granule cells. $d b / d b$ mice infused with vehicle had fewer spines than WT mice, but after 2 weeks of IL1 ra infusion, $d b / d b$ mice exhibit dendritic spine density that is indistinguishable from WT mice (Fig. $7 E, F ; F_{(1,12)}=$ $15.25, p=0.002$, post hoc Bonferroni's-corrected $t$ test, vehicleinfused WT vs vehicle-infused $d b / d b, t_{(7)}=4.92, p=0.002$, all other comparisons not significant). This effect was not restricted to neurons sampled for morphological analysis, because we observed parallel changes in protein expression for the synaptic markers PSD95 (Fig. 7G,I; $F_{(1,8)}=4.40, p=0.04$, post hoc Bonferroni's-corrected $t$ test, vehicle-infused WT vs vehicleinfused $d b / d b, t_{(7)}=2.17, p=0.009$, all other comparisons not significant), spinophilin (Fig. $7 H, I ; F_{(1,8)}=8.87, p=0.04$, post hoc Bonferroni's-corrected $t$ test, vehicle-infused WT vs vehicleinfused $d b / d b, t_{(7)}=3.01, p=0.01$, all other comparisons not significant), and synaptophysin (Fig. $7 \mathrm{~J}, I ; F_{(1,8)}=4.38, p=0.03$, post hoc Bonferroni's-corrected $t$ test, vehicle-infused WT vs vehicle-infused $d b / d b, t_{(7)}=2.94, p=0.01$, all other comparisons not significant) by Western blotting in whole-hippocampal homogenates. The restoration of function that we observed at the behavioral, electrophysiological, structural, and molecular levels strongly supports a role for IL1 as a mediator of synaptic dysfunction in obesity and diabetes.

\section{Discussion}

We observed that increased exposure to the proinflammatory cytokine IL1 $\beta$ mediates hippocampal dysfunction in a genetic mouse model of obesity and diabetes. $d b / d b$ mice exhibit increased levels of IL1 $\beta$ in hippocampus and adipose tissue, and these increases are reversible by increasing physical activity, suggesting that they are not a direct consequence of leptin receptor insufficiency. Moreover, microglia exhibit in vivo and ex vivo evidence for sensitization in $d b / d b$ mice, and this is likely attributable to increased exposure to circulating factors, such as IL1 $\beta$. Ex vivo sensitization is reversible via treadmill training-induced or surgical reductions in adiposity, indicating that adipose tissue is a primary source for proinflammatory cytokines that negatively regulate synaptic plasticity and cognition. Intrahippocampal administration of an IL1ra upheld the essential role of this proinflammatory cytokine as a mechanism for neurocognitive dysfunction in $d b / d b$ mice. Together, these studies suggest that excessive adiposity generates immune responses that lead to cognitive impairment.

The current study focuses on the role of inflammation as a mechanism for cognitive impairment in obesity, but the cellular source that initiates production of proinflammatory cytokines remains to be determined. Given previous reports of blood-brain barrier breakdown in obesity (Kanoski et al., 2010), the composition of immune cells residing in the $d b / d b$ mouse hippocampus is likely to differ from the cellular makeup of WT mice. Given that microglia under normal conditions are not a particularly robust source of MHCII (Soulet and Rivest, 2008), the antigen-presenting cells in the $d b / d b$ mice are more likely to be a mixed population of perivascular macrophages and peripherally derived macrophages that have penetrated the blood-brain barrier. Given previous studies demonstrating an essential role for perivascular macrophages in the initiation of proinflammatory cascades in the brain after infection (Audoy-Rémus et al., 2008; Serrats et al., 2010), this seems the most probable source for obesity-induced increases in IL1 $\beta$.

We observed no effect of the treadmill training paradigm on any parameter in WT mice. This contrasts with some previous studies, but the intensity of the training protocol in the current experiments is far lower than the level of activity typ- 
A

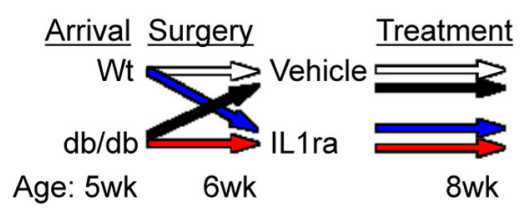

D

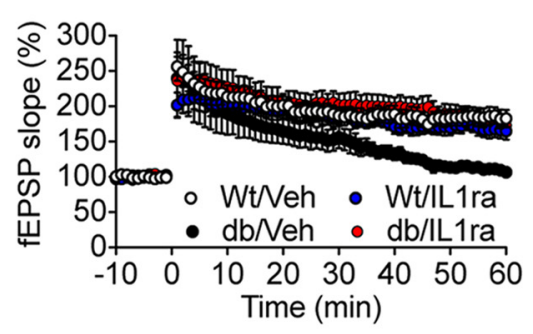

$\mathbf{F}$

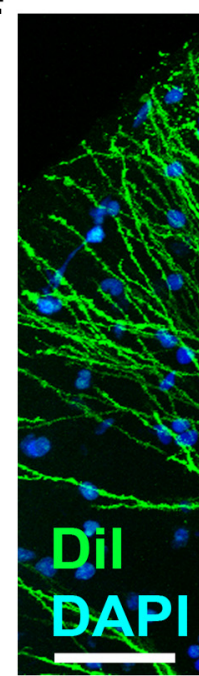

I

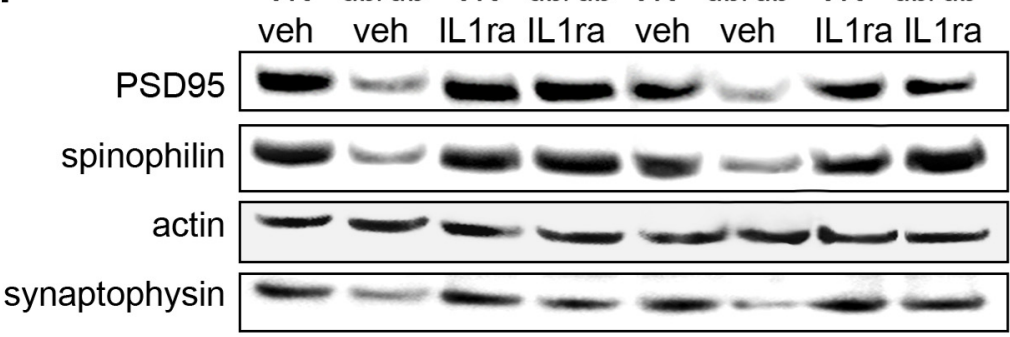

B
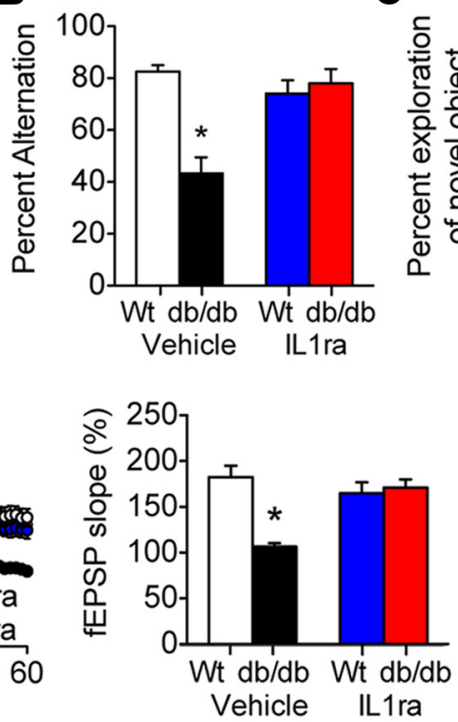

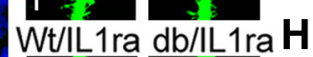

WtNeh dbNeh $\mathbf{G}$
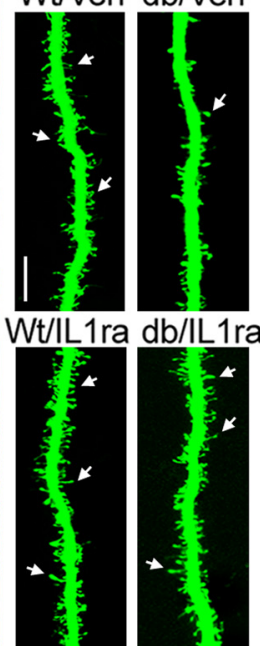

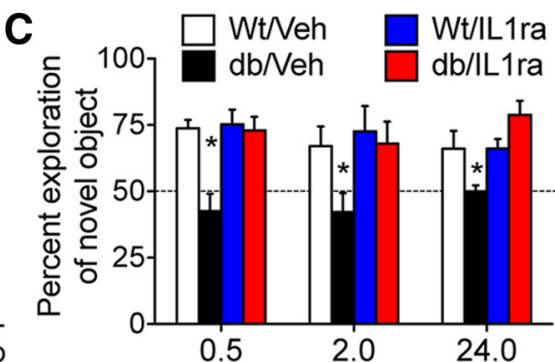

Time post-training (hr)

E

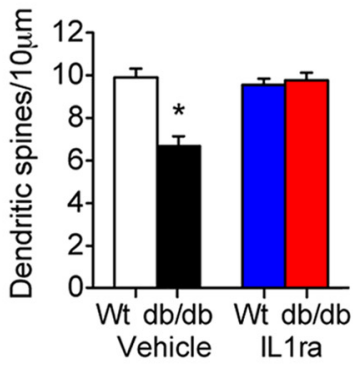

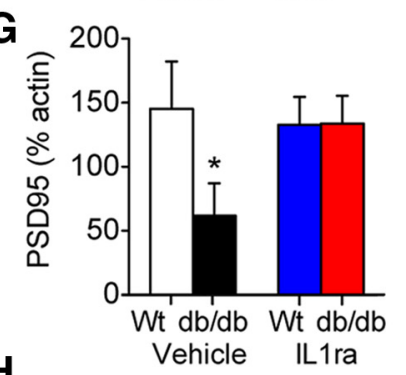

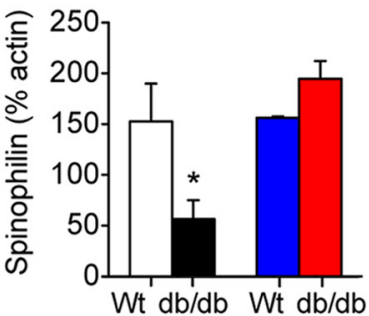

$J$

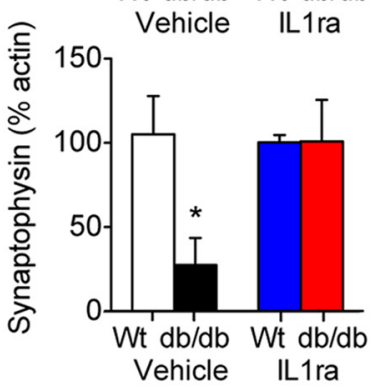

Figure 7. Intrahippocampal infusions of IL1ra reinstate memory and synaptic plasticity in $d b / d b$ mice. $A$, Experimental design. $B$, Analysis of spatial recognition memory in the $Y$-maze revealed that 2 weeks of intrahippocampal IL 1 ra infusion abolished memory deficits in $\mathbf{d b} / \mathbf{d b}$ mice. C, Assessment of object-recognition memory revealed similar trends at all time points examined. $\boldsymbol{D}$, Parallel alterations in dentate gyrus LTP were observed, with impairment in vehicle-infused $d b / d b$ mice, but not in $d b / d b$ mice, infused with IL $1 \mathrm{ra}$. The right graph depicts the percentage increase in the slope of the fEPSP during the last $10 \mathrm{~min}$ of the recording. $\boldsymbol{E}$, Quantification of dendritic spine density among dentate gyrus granule neurons revealed that IL 1 ra infusions reverse deficits in $d b / d b$ mice. $\boldsymbol{F}$, Low-power micrograph shows dentate gyrus granule cells labeled with Dil; higher-power images at the right depict dendritic segments from each treatment group. Arrows indicate dendritic spines. Scale bar, $5 \mu \mathrm{m}$. G, Analysis of PSD95 expression in whole-hippocampal homogenates indicates that intrahippocampal treatment with IL1ra reverses deficits in expression of this synaptic marker. $\boldsymbol{H}$, Parallel alterations in spinophilin expression were observed in Western blot experiments. $\boldsymbol{I}$, Protein expression of the presynaptic marker synaptophysin revealed similar trends.J, Representative Western blot images from the indicated groups. For all graphs, ${ }^{*} p<0.05$ relative to vehicle-infused WT mice after $2 \times 2$ ANOVA or $2 \times 2$ repeated-measures ANOVA when appropriate, with Bonferroni's-corrected post hoc $t$ tests. Error bars represent the SEM.

ically used to influence neuroplasticity in rodents. Mice in the current study ran $4 \mathrm{~km} /$ week on the treadmill to clamp activity levels to that reported previously in 5-week-old $d b / d b$ mice housed with running wheels (Stranahan et al., 2009). In con- trast, a 5-week-old WT mouse will exhibit $>10 \mathrm{~km} /$ week voluntary wheel running (Clark et al., 2009; Stranahan et al., 2009). Based on the disparity between levels of activity under the current protocol and levels of voluntary activity in a run- 
ning wheel, it is not particularly surprising that there was no effect of this minimal amount of treadmill running on any parameter in WT mice.

We examined synaptic plasticity with a focus on the dentate gyrus, the predominant point of entry for cortical afferents to the hippocampus. Although the dentate has primarily received attention because of ongoing neurogenesis in this region, the current studies used pharmacological strategies and morphological criteria to focus on the far more numerous mature granule cell population. Numerous reports suggest that mature dentate gyrus neurons are functionally silent (Alme et al., 2010) based on the results of single-unit recording studies conducted under low stress conditions. However, activation of dentate gyrus granule cells is strongly modulated by amygdalar input (Korz and Frey, 2005), opening the possibility that the apparent silence among mature granule cells simply reflects their preferential recruitment under emotionally salient conditions. Because obesity and diabetes are accompanied by increased prevalence of stress and anxiety, it is likely that changes among dentate gyrus granule cells would be particularly significant under these conditions. However, more work remains to be done to elucidate mechanisms that link hippocampal dysfunction to dysregulation of stress responses in obesity.

Together, this series of studies demonstrates that adipose tissue-derived cytokines gain entry to the hippocampus and impair synaptic plasticity and cognition. We observed that fat transplantation from genetically obese mice into WT mice elicits memory impairment. Other studies using diet-induced obesity have reported correlated expansion of adipose tissue, neuroinflammation, and cognitive impairment (Jeon et al., 2012), suggesting that adiposity-induced inflammation, rather than the genetic or environmental factors that elicit this phenotype, accounts for hippocampal synaptic dysfunction. However, future studies using WT mice on a high-fat diet as donors for fat transplantation experiments will be necessary to more directly assess the relationship between adiposity, neuroinflammation, and cognitive dysfunction.

Our observation of parallel changes in learning and memory across spatial and object-recognition memory tasks that may differ in terms of their recruitment of medial temporal lobe structures underscores the strength of the relationship between obesity-induced inflammation and cognition. This observation does not implicate all adipose tissue depots as a uniform source for factors that impair learning and memory. We targeted the epididymal fat pad because of its responsivity to the treadmill manipulation, but other studies manipulating subcutaneous fat indicate that this depot may actually be protective, at least with regard to metabolic endpoints (Tran et al., 2008). Therefore, the consequences of adiposity for inflammatory cytokines and synaptic function may differ depending on the distribution of fat across various compartments. The evidence for negative clinical outcomes with central deposition of fat is clear in that visceral adiposity correlates with impaired glucoregulation and chronic inflammation (Kanneganti and Dixit, 2012). These features are increasingly recognized as correlates and perhaps mediators of cognitive impairment (Whitmer et al., 2008). Investigation of this cascade could identify novel targets for the treatment and prevention of cognitive decline in vulnerable populations, such as the growing clinical population of individuals with features of the metabolic syndrome.

\section{References}

Allen PB, Ouimet CC, Greengard P (1997) Spinophilin, a novel protein phosphatase 1 binding protein localized to dendritic spines. Proc Natl Acad Sci U S A 94:9956-9961. CrossRef Medline

Alme CB, Buzzetti RA, Marrone DF, Leutgeb JK, Chawla MK, Schaner MJ, Bohanick JD, Khoboko T, Leutgeb S, Moser EI, Moser MB, McNaughton BL, Barnes CA (2010) Hippocampal granule cells opt for early retirement. Hippocampus 20:1109-1123. CrossRef Medline

Audoy-Rémus J, Richard JF, Soulet D, Zhou H, Kubes P, Vallières L (2008) Rod-Shaped monocytes patrol the brain vasculature and give rise to perivascular macrophages under the influence of proinflammatory cytokines and angiopoietin-2. J Neurosci 28:10187-10199. CrossRef Medline

Barrientos RM, Sprunger DB, Campeau S, Higgins EA, Watkins LR, Rudy JW, Maier SF (2003) Brain-derived neurotrophic factor mRNA downregulation produced by social isolation is blocked by intrahippocampal interleukin-1 receptor antagonist. Neuroscience 121:847-853. CrossRef Medline

Clark PJ, Brzezinska WJ, Puchalski EK, Krone DA, Rhodes JS (2009) Functional analysis of neurovascular adaptations to exercise in the dentate gyrus of young adult mice associated with cognitive gain. Hippocampus 19:937-950. CrossRef Medline

Coleman DL (1978) Obese and diabetes: two mutant genes causing diabetes-obesity syndromes in mice. Diabetologia 14:141-148. CrossRef Medline

Dinel AL, André C, Aubert A, Ferreira G, Layé S, Castanon N (2011) Cognitive and emotional alterations are related to hippocampal inflammation in a mouse model of metabolic syndrome. PLoS One 6:e24325. CrossRef Medline

Fadel JR, Jolivalt CG, Reagan LP (2013) Food for thought: The role of appetitive peptides in age-related cognitive decline. Ageing Res Rev 12:764776. CrossRef Medline

Feng J, Yan Z, Ferreira A, Tomizawa K, Liauw JA, Zhuo M, Allen PB, Ouimet CC, Greengard P (2000) Spinophilin regulates the formation and function of dendritic spines. Proc Natl Acad Sci U S A 97:9287-9292. CrossRef Medline

Fourgeaud L, Davenport CM, Tyler CM, Cheng TT, Spencer MB, Boulanger LM (2010) MHC class I modulates NMDA receptor function and AMPA receptor trafficking. Proc Natl Acad Sci U S A 107:22278-22283. CrossRef Medline

Frank MG, Wieseler-Frank JL, Watkins LR, Maier SF (2006) Rapid isolation of highly enriched and quiescent microglia from adult rat hippocampus: immunophenotypic and functional characteristics. J Neurosci Methods 151:121-130. CrossRef Medline

Ge S, Goh EL, Sailor KA, Kitabatake Y, Ming GL, Song H (2006) GABA regulates synaptic integration of newly generated neurons in the adult brain. Nature 439:589-593. CrossRef Medline

Harris RB, Hausman DB, Bartness TJ (2002) Compensation for partial lipectomy in mice with genetic alterations of leptin and its receptor subtypes. Am J Physiol Regul Integr Comp Physiol 283:R1094-R1103. CrossRef Medline

Henderson YO, Smith GP, Parent MB (2013) Hippocampal neurons inhibit meal onset. Hippocampus 23:100-107. CrossRef Medline

Jeon BT, Jeong EA, Shin HJ, Lee Y, Lee DH, Kim HJ, Kang SS, Cho GJ, Choi WS, Roh GS (2012) Resveratrol attenuates obesity-associated peripheral and central inflammation and improves memory deficit in mice fed a high-fat diet. Diabetes 61:1444-1454. CrossRef Medline

Kanneganti TD, Dixit VD (2012) Immunological complications of obesity. Nat Immunol 13:707-712. CrossRef Medline

Kanoski SE, Zhang Y, Zheng W, Davidson TL (2010) The effects of a highenergy diet on hippocampal function and blood-brain barrier integrity in the rat. J Alzheimers Dis 21:207-219. CrossRef Medline

Korz V, Frey JU (2005) Bidirectional modulation of hippocampal longterm potentiation under stress and no-stress conditions in basolateral amygdala-lesioned and intact rats. J Neurosci 25:7393-7400. CrossRef Medline

O'Connor JC, Satpathy A, Hartman ME, Horvath EM, Kelley KW, Dantzer R, Johnson RW, Freund GG (2005) IL-1beta-mediated innate immunity is amplified in the $d b / d b$ mouse model of type 2 diabetes. J Immunol 174: 4991-4997. Medline

Odegaard JI, Chawla A (2013) Pleiotropic actions of insulin resistance and inflammation in metabolic homeostasis. Science 339:172-177. CrossRef Medline 
Rooks C, Bennet T, Bartness TJ, Harris RB (2004) Compensation for an increase in body fat caused by donor transplants into mice. Am J Physiol Regul Integr Comp Physiol 286:R1149-R1155. CrossRef Medline

Serrats J, Schiltz JC, García-Bueno B, van Rooijen N, Reyes TM, Sawchenko PE (2010) Dual roles for perivascular macrophages in immune-to-brain signaling. Neuron 65:94-106. CrossRef Medline

Soulet D, Rivest S (2008) Bone-marrow derived microglia: myth or reality? Curr Opinion Pharmacol 8:508-18. CrossRef Medline

Stranahan AM, Mattson MP (2012) Recruiting adaptive cellular stress responses for successful brain ageing. Nat Rev Neurosci 13:209-216. CrossRef Medline

Stranahan AM, Arumugam TV, Cutler RG, Lee K, Egan JM, Mattson MP (2008a) Diabetes impairs hippocampal function through glucocorticoidmediated effects on new and mature neurons. Nat Neurosci 11:309-317. CrossRef Medline

Stranahan AM, Norman ED, Lee K, Cutler RG, Telljohann RS, Egan JM, Mattson MP (2008b) Diet-induced insulin resistance impairs hippocampal synaptic plasticity and cognition in middle-aged rats. Hippocampus 18:1085-1088. CrossRef Medline

Stranahan AM, Lee K, Martin B, Maudsley S, Golden E, Cutler RG, Mattson MP (2009) Voluntary exercise and caloric restriction enhance hip- pocampal dendritic spine density and BDNF levels in diabetic mice. Hippocampus 19:951-961. CrossRef Medline

Stranahan AM, Haberman RP, Gallagher M (2011) Cognitive decline is associated with reduced reelin expression in the entorhinal cortex of aged rats. Cereb Cortex 21:392-400. CrossRef Medline

Tran TT, Yamamoto Y, Gesta S, Kahn CR (2008) Beneficial effects of subcutaneous fat transplantation on metabolism. Cell Metab 7:410-420. CrossRef Medline

Whitmer RA, Gustafson DR, Barrett-Connor E, Haan MN, Gunderson EP, Yaffe K (2008) Central obesity and increased risk of dementia more than three decades later. Neurology 71:1057-1064. CrossRef Medline

Wisse BE, Schwartz MW (2009) Does hypothalamic inflammation cause obesity? Cell Metab 10:241-242. CrossRef Medline

Wosiski-Kuhn M, Stranahan AM (2012) Transient increases in dendritic spine density contribute to dentate gyrus long-term potentiation. Synapse 66:661-664. CrossRef Medline

Xu W, Caracciolo B, Wang HX, Winblad B, Bäckman L, Qiu C, Fratiglioni L (2010) Accelerated progression from mild cognitive impairment to dementia in people with diabetes. Diabetes 59:2928-2935. CrossRef Medline 